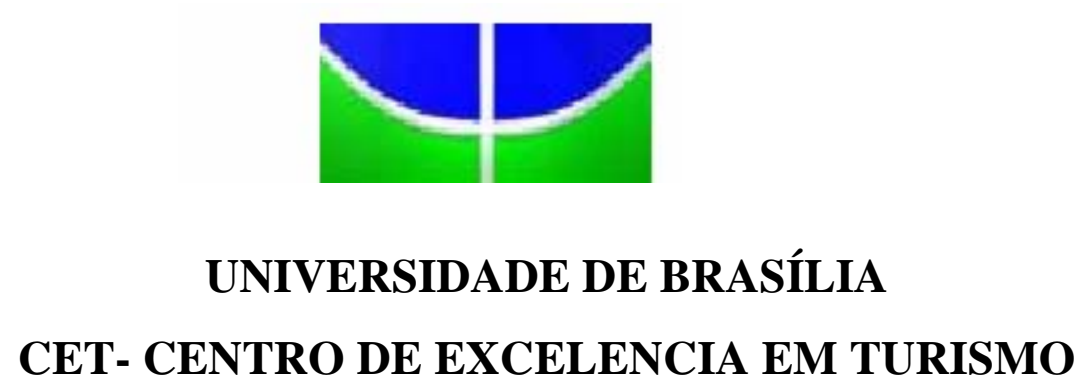

Pós-graduação Lato Sensu

Curso de Especialização em Qualidade em alimentos

\title{
ALIMENTAÇÃO DO PRÉ-ESCOLAR E ESCOLAR E AS ESTRATÉGIAS DE EDUCAÇÃO NUTRICIONAL
}

PRISCILLA MARIA OLIVEIRA DE SOUSA 


\section{UNIVERSIDADE DE BRASÍLIA \\ CET - CENTRO DE EXCELÊNCIA EM TURISMO}

Curso de Especialização em Qualidade em alimentos

\section{ALIMENTAÇÃO DO PRÉ-ESCOLAR E ESCOLAR E AS ESTRATÉGIAS DE EDUCAÇÃO NUTRICIONAL}

PRISCILLA MARIA OLIVEIRA DE SOUSA

Wilma Araújo, Doutora

Professor Coordenador
Fabiana Nalon, Especialista

Professor Orientador
Nancy, Especialista Professor Examinador

"Trabalho apresentado em cumprimento às exigências acadêmicas parciais do curso de pós-graduação lato sensu em Qualidade e alimentos para a obtenção do grau de Especialista"

Brasília - DF

Maio/ 2006. 
SOUSA, Priscilla Maria Oliveira

Alimentação do Pré-Escolar e Escolar e as Estratégias de Educação Nutricional/ Priscilla Maria Oliveira Sousa

Monografia - Curso de Especialização em Qualidade em Alimentos

Orientador: Fabiana Nalon

1. Alimentação Infantil 2. Educação Nutricional 


\section{DEDICATÓRIA}

Dedico este trabalho a minha amiga e sócia, Mônica de Morais, que junto comigo tornou realidade um sonho: O Projeto Cultura Alimentar e Qualidade de Vida. 


\section{AGRADECIMENTOS}

Agradeço a todas as pessoas que me incentivaram e ajudaram a percorrer mais este caminho. Que todas elas continuem presentes em minha vida, tornando ela ainda mais iluminada. 


\section{RESUMO}

Este trabalho pretendeu consolidar informações sobre a situação nutricional de crianças em fase pré-escolar e escolar, considerando as estratégias de políticas públicas dentro de um contexto de educação nutricional desmembrada em projetos escolares. O trabalho considerou os vários aspectos que influenciam na alimentação deste grupo de indivíduos e como eles podem ser articulados a favor deles próprios através de uma intervenção direta ou indireta. Foi possível concluir que os fatores de influencias quando trabalhados de forma positiva em casa, na escola, bem como pelo Estado e sociedade podem reverter os quadros de obesidade e desnutrição da criança. 


\section{SUMÁRIO}

INTRODUÇÃO

METODOLOGIA...........................................................................

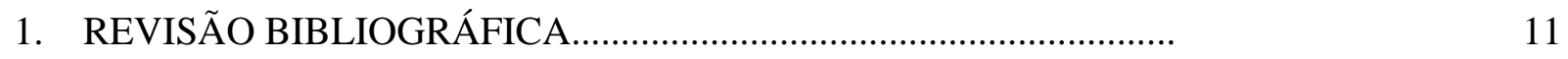

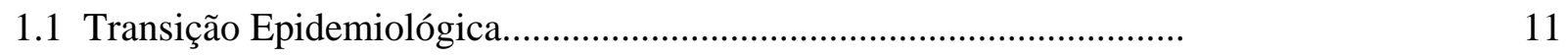

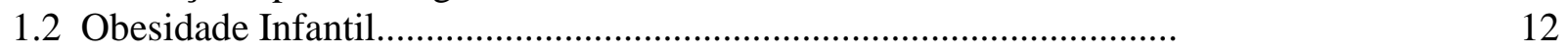

1.3 Segurança Alimentar e combate a desnutrição....................................... 15

1.4 A Importância do acompanhamento do crescimento e 16

desenvolvimento do pré-escolar e escolar e as necessidades energéticas...

$1.5 \mathrm{O}$ desenvolvimento das escolhas alimentares em crianças e adolescentes.

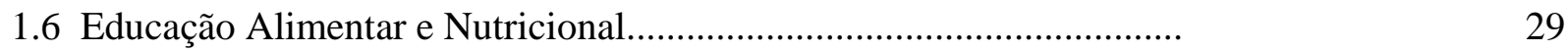

2. POLÍTICAS PÚBLICAS DE ALIMENTAÇÃO E NUTRIÇÃO......... 37

2.1 Alimentação Escolar no Brasil: Evolução Histórica................................ 38

2.2 Programa Fome Zero e a Educação Nutricional....................................

2.3 Lei das Cantinas Escolares no Distrito Federal................................... 42

3. PROJETO: CULTURA ALIMENTAR E QUALIDADE DE VIDA.. 44

CONCLUSÃO............................................................................

REFERÊNCIAS BIBLIOGRÁFICAS............................................

ANEXO 


\section{INTRODUÇÃO}

A alimentação da criança desde o nascimento e nos primeiros anos de vida tem repercussões ao longo de toda a vida. É considerada como um dos fatores mais importantes para a saúde da criança. Nesta fase, além de suprir as necessidades nutricionais, também é uma das principais formas de contato com o mundo externo.

O comportamento alimentar das crianças, assim como as suas preferências alimentares, são influenciadas por fatores genéticos ou hereditários e também por fatores ambientais. Nestes últimos estão incluídas as relações sociais, que poderão influenciar positivamente ou negativamente.

À medida que a criança começa a freqüentar outros ambientes, como a escola, se inicia uma intensa socialização, onde novas influências serão sofridas. Há uma grande tendência em repetir o comportamento de professores e de outras crianças, que podem ser bons ou ruins. Por isso a necessidade do incentivo de uma alimentação saudável em grupo.

Outro fator de influência na alimentação infantil é uma resposta inata de neofobia alimentar (aversão e rejeição a alimentos novos), comum nas crianças até os dois anos, mas que diminui com a exposição repetida a novos alimentos (ANDRADE, 2005). A neofobia deve ser encarada como uma resposta normal ou de adaptação da criança em desenvolvimento. A aceitação de novos alimentos ocorre de forma progressiva e natural

A televisão é também um fator de influência, na maioria das vezes negativa Um estudo da disciplina de Nutrologia, ligada ao Departamento de Pediatria da UNIFESP, analisou durante um mês o conteúdo das campanhas publicitárias de produtos alimentícios voltadas para crianças veiculadas nos intervalos de programas infantis de televisão, concluindo que, a cada 10 minutos de exibição, 1 minuto tem como objetivo estimular o consumo de produtos alimentícios com alto teor de gordura saturada e açúcar refinado. Segundo a Organização Mundial de Saúde, 30 segundos de propaganda já seriam suficientes para exercer forte influência (UNIFESP, 2005). 
Tais produtos alimentícios de valor nutricional questionável, são anunciados nos intervalos de programas exclusivamente infantis.

O somatório dos fatores comportamentais e sociais pode levar a criança a construir hábitos alimentares inadequados e as conseqüências para a saúde são notórias.

A alimentação e a nutrição constituem requisitos básicos para a promoção e a proteção da saúde, possibilitando a afirmação plena do potencial de crescimento e desenvolvimento humano, com qualidade de vida e cidadania. No plano individual e em escala coletiva, esses atributos estão consignados na Declaração Universal dos Direitos Humanos, promulgada há 50 anos, os quais foram posteriormente reafirmados no Pacto Internacional sobre Direitos Econômicos, Sociais e Culturais (1966) e incorporados à legislação nacional em 1992 (MS, 2003).

Diante desta situação apresenta -se a necessidade urgente de programas escolares voltados para a saúde, nutrição e qualidade de vida, para que em um processo de educação nutricional as crianças possam aprender a se alimentar com qualidade. É necessário ensiná-las o quanto antes, como escolher os alimentos que irão consumir. Dessa forma é possível construir hábitos alimentares que irão repercutir de forma positiva na vida da criança e por conseguinte torná-la um adulto saudável.

Este trabalho tem por objetivo analisar por meio de revisão literária a alimentação de préescolares e escolares, considerando suas determinantes psicossociais, emocionais, econômicos e suas conseqüências para a saúde, bem como as políticas públicas em alimentação relacionadas á obesidade infantil e apresentar o projeto: Cultura Alimentar e Qualidade de Vida, implementado em uma escola particular do Distrito Federal no ano de 2005. 


\section{METODOLOGIA}

Dentro dos parâmetros estabelecidos para o presente trabalho utilizou-se a perspectiva da tipologia teórica onde todo o desenvolvimento se deu através de pesquisa bibliográfica sobre o assunto, cuja coleta de dados foi fundamental para o desenvolvimento do trabalho.

A presente pesquisa se desenvolveu inicialmente com o reconhecimento primordial das questões envolvidas na transição nutricional e epidemiológica considerando a população de préescolares e escolares. Também foram discutidas neste trabalho as escolhas alimentares de préescolares e escolares, as de ações de educação nutricional, as políticas públicas referentes a nutrição infantil, além de uma proposta de trabalho em uma escola, que trata o tema educação nutricional de forma incisiva. As principais fontes de pesquisa foram artigos científicos provenientes do banco de dados da Scielo e do Google. Também foram utilizados livros específicos em alimentação infantil, desnutrição e obesidade.

O trabalho ficou dividido em três capítulos. O primeiro deles trata sobre a transição nutricional e epidemiológica, relata as ações de educação nutricional e a sua relação com educadores pais e escola. O segundo capítulo aborda as políticas públicas em alimentação infantil e o programa fome zero como precursor da educação alimentar e nutricional. O terceiro capítulo apresenta o projeto: Cultura alimentar e Qualidade de Vida, implantado em uma escola particular do Distrito Federal no ano de 2005. 


\section{REVISÃo LITERÁRIA}

\subsection{TRANSIÇÃO NUTRICIONAL E EPIDEMIOLÓGICA}

No Brasil, tem sido detectada a progressão da transição nutricional, caracterizada pela redução na prevalência dos déficits nutricionais e ocorrência mais expressiva de doenças crônicodegenerativas associadas ao sobrepeso e obesidade. Tal fato ocorre não apenas na população adulta, mas também em crianças e adolescentes. Segundo teorias ambientalistas, as causas estão fundamentalmente ligadas às mudanças no estilo de vida e aos hábitos alimentares. Confirmando essas teorias, verifica-se que a obesidade é mais freqüente em regiões mais desenvolvidas do país, pelas mudanças de hábitos associadas a esse processo. O consumo alimentar tem sido relacionado à obesidade não somente quanto ao volume da ingestão de alimentos, como também à composição e qualidade da dieta. As mudanças nos padrões alimentares explicam em parte o contínuo aumento da adiposidade nas crianças. Nota-se, por exemplo, o baixo consumo de frutas, hortaliças e leite, o aumento no consumo de guloseimas e refrigerantes, bem como a omissão do café da manhã (GUIMARÃES, BARROS, 2001; MONDINI, MONTEIRO 1998).

As transformações sociais, econômicas e demográficas ocorridas globalmente, durante as duas últimas décadas, coincidiram com alterações no perfil epidemiológico nos padrões alimentares e de atividades físicas, conferindo heterogêneos padrões nutricionais em diferentes situações e que, especialmente, entre adultos, tanto em países desenvolvidos como em algumas regiões de países em desenvolvimento, enfraquecem as associações de desnutrição e enfermidades transmissíveis com a pobreza; e da obesidade e enfermidades crônicas com bemestar econômico (TONIAL, 2003).

Um levantamento feito pela Organização Pan-americana de Saúde, revelou que a obesidade infanto-juvenil no Brasil avançou 240\% nos últimos 20 anos. Estima-se que entre 20\% e $25 \%$ das crianças e dos adolescentes brasileiros sofram de obesidade ou sobrepeso (COSTA e ALVES, 2005). 


\section{Obesidade Infantil}

Uma em cada dez crianças em todo mundo - 155 milhões - é obesa. O número, um sério indicador de que a obesidade infantil tomou proporções epidêmicas, está no relatório da forçatarefa Internacional sobre obesidade, enviado à Organização Mundial da saúde (OMS). No Brasil os dados são extremamente preocupantes e também colocam a obesidade infantil como um problema grave de saúde pública. Nos últimos 20 anos, a obesidade infantil triplicou. Hoje, 40\% da população brasileira está acima do peso, e 6\% da população desnutrida. Isso significa que quase metade da população tem problemas alimentares. Considerando o quadro de obesidade infantil, quase 15\% das crianças têm excesso de peso e 5\% são obesas (SBEM, 2006).

A obesidade na infância está se apresentando como uma epidemia global. Nas últimas décadas duplicou a incidência da obesidade entre as crianças e adolescentes. Nos Estados Unidos aproximadamente 25\% das crianças entre 6 e 17 anos são obesas ou apresentam risco de sobrepeso. A obesidade representa nos Estados Unidos a doença nutricional mais prevalente entre crianças e adolescentes. Nas nações em desenvolvimento, a obesidade coexiste com a desnutrição, provavelmente pela modificação dos hábitos e estilo de vida, que se tornaram mais “americanizados”. Como a criança obesa tem um maior risco de tornar-se um adulto obeso, poderá haver conseqüências profundas na saúde publica nos próximos anos como resultado das co-morbidades associadas à obesidade (ABESO, 2003).

Vários fatores são importantes na gênese da obesidade, como os genéticos, os fisiológicos e os metabólicos; no entanto, os que poderiam explicar este crescente aumento do número de indivíduos obesos parecem estar mais relacionados às mudanças no estilo de vida e aos hábitos alimentares (OLIVEIRA E FISBERG, 2003).

A obesidade parece ser condição familiar, crianças com idade entre 3 e 10 anos com pais obesos têm o dobro de chances de tornar-se adultos obesos quando comparadas com crianças obesas cujos pais não são obesos. Também foi demonstrado que a inatividade da família prediz a inatividade da criança. A atividade física dos pais influencia a freqüência de exercício dos seus filhos. (ABESO, 2003). 
O aumento no consumo de alimentos ricos em açúcares simples e gordura, com alta densidade energética, e a diminuição da prática de exercícios físicos, são os principais fatores relacionados ao meio ambiente. O estudo de Oliveira et al., verificou que a obesidade infantil foi inversamente relacionada com a prática da atividade física sistemática, com a presença de TV, computador e videogame nas residências, além do baixo consumo de verduras, confirmando a influência do meio ambiente sobre o desenvolvimento do excesso de peso em nosso meio. Outro achado importante foi o fato da criança estudar em escola privada e ser unigênita, como os principais fatores preditivos na determinação do ganho excessivo de peso, demonstrando a influência do fator sócio-econômico e do micro-ambiente familiar. O acesso mais fácil aos alimentos ricos em gorduras e açúcares simples, assim como, aos avanços tecnológicos, como computadores e videogames, poderia explicar de certa forma a maior prevalência da obesidade encontrada nas escolas particulares. Contudo, esses dados não estão de acordo com os encontrados em países desenvolvidos, onde existe uma relação inversa entre o nível de educação ou sócio-econômico e a obesidade (OLIVEIRA E FISBERG, 2003).

A obesidade pode iniciar em qualquer idade, desencadeada por fatores como o desmame precoce, a introdução inadequada de alimentos, distúrbios do comportamento alimentar e da relação familiar, especialmente nos períodos de aceleração do crescimento. Whitaker et al. e Price, relatam a necessidade da identificação precoce do excesso de peso em crianças para diminuir o risco de se tornarem adultos obesos. Os autores enfatizam dois fatores que podem contribuir para dobrar o risco da obesidade em adultos jovens: obesidade em um dos pais ou sua presença na infância. Ambos os fatores não devem ser considerados isoladamente, mas em interação. Cutting et al., concluem que o modelo de comportamento tendendo à inatividade e inadequação da dieta familiar é um fator que pode levar à obesidade precoce. Por outro lado, a inter-relação com jovens atletas e a orientação e motivação pelos pais foram relatados como influências positivas na prevenção da obesidade (GIUGLIANO E CARNEIRO, 2004).

O Instituto Nacional de Alimentação e Nutrição (INAN) aponta que a obesidade infantil no Brasil atinge $16 \%$ das crianças. No Brasil, as crianças mais atingidas pela obesidade ainda pertencem às classes sociais mais privilegiadas, apesar da tendência recente de uma mudança nesse perfil. (GIUGLIANO E MELO, 2004). 
Observa-se também na PNAN que há uma maior abrangência no enfoque dos problemas nutricionais, passando a considerar a obesidade como alvo das políticas, ao lado do combate à fome e à desnutrição. Isso corresponde ao quadro alimentar-nutricional vigente, caracterizado por uma expressiva redução da desnutrição energético-protéica, concomitante a um aumento do sobrepeso e obesidade em todas as classes sociais (SANTOS, 20005).

Maus hábitos alimentares, especialmente aqueles que acarretam a obesidade infantil, produzem problemas de saúde imediatos e também em longo prazo, visto que cerca de $60 \%$ de crianças obesas já sofrem de hipertensão, hiperlipidemia e/ou hiperinsulinemia (ALMEIDA, NASCIMENTO E QUAIOTI, 2002).

A obesidade infantil também está relacionada a outras doenças que antes eram conhecidas apenas em adultos, como o infarto do miocárdio, acidente vascular cerebral (derrame), doenças do aparelho respiratório e locomotor, doença da vesícula biliar e até vários tipos de câncer. Crianças de 7 anos de idade já são portadoras de diabetes tipo 2, que, antes se manifestava apenas em pessoas com ais de 40 anos (SBEM, 2006).

“A discriminação, a estigmatização, a dificuldade de relacionamento com o sexo oposto, as dificuldades de lazer, de transporte, as frustrações nos esportes, somente para citar algumas, faz com que, na nossa sociedade, a criança obesa seja vista como um cidadão de segunda categoria” (VIUNISKI, 2005).

\section{Segurança Alimentar e Combate á Desnutrição}

O problema da fome e da desnutrição no Brasil está estreitamente vinculado à limitação do acesso ao alimento. Cerca de 54 milhões de brasileiros não dispõem de recursos suficientes para atender suas necessidades básicas, sendo que algo em torno da metade dessas pessoas vive em situação de indigência, possuindo uma renda que permite, apenas, a compra de uma cesta básica de alimentos (ABRINQ, 2004). Segundo a OMS, a nutrição adequada é o principal fator para o crescimento e desenvolvimento normais (MAZZILLI, 1987). 
No Brasil, verifica-se nas últimas décadas um processo de transição nutricional, constatando-se que entre os anos 1974/75 e 1989, houve uma redução da prevalência da desnutrição infantil de 19,8\% para 7,6\% (OLIVEIRA E FISBERG, 2003).

Cabe destacar que, apesar de ainda ser necessário efetivar esforços para reduzir a desnutrição infantil no Brasil, essa situação já se encontra em declínio há aproximadamente duas décadas. Ao se analisar os três inquéritos nacionais disponíveis - realizados em 1975, 1989 e 1997 - observa-se uma nítida queda na prevalência de baixa estatura nas crianças menores de 5 anos de idade situadas entre os quartis populacionais mais pobres e mais ricos da população. Um exemplo disso é que, considerando os $25 \%$ mais pobres, a prevalência de baixa estatura, que era de $60,8 \%$ em 1975, passou para 28,8\% em 1997. Isso ocorreu em virtude da intensificação de investimentos governamentais, principalmente no setor saúde, que culminaram na redução substancial da natalidade, na melhoria do saneamento básico, na proteção contra doenças infectocontagiosas - com especial destaque à prevenção de agravos imunopreveníveis, na elevação do nível da escolaridade das mães, e na melhoria das condições de acesso às ações básicas de saúde. A associação dessas estratégias com os programas e ações de nutrição, operados pelo setor saúde - tais como o incentivo ao aleitamento materno, o Programa Nacional de Suplementação Alimentar, o Programa Nacional de Combate às Carências Nutricionais, o Programa Bolsa Alimentação e os Programas emergenciais de distribuição de cestas básicas, proporcionaram um considerável declínio da desnutrição em crianças menores de 5 anos nos últimos anos. (ABRINQ, 2004).

Ao mesmo tempo em que declina a ocorrência da desnutrição em crianças e adultos num ritmo bem acelerado, aumenta a prevalência de sobrepeso e obesidade na população brasileira. A projeção dos resultados de estudos efetuados nas últimas três décadas é indicativa de um comportamento claramente epidêmico do problema. Estabelece-se, dessa forma, um antagonismo de tendências temporais entre desnutrição e obesidade, definindo uma das características marcantes do processo de transição nutricional do país (FILHO E RISSIN, 2003) .

Em um país como o Brasil, onde as desigualdades sociais e regionais são imensas, é importante destacar que a garantia da segurança alimentar e nutricional pressupõe a necessidade de estratégias de saúde pública capazes de dar conta de um modelo de atenção à saúde e de 
cuidado nutricional direcionados para desnutrição e sobrepeso/obesidade, uma vez que esses distúrbios nutricionais e todas as doenças relacionadas à alimentação e à nutrição revelam duas faces, diversas e aparentemente paradoxais, de um mesmo problema: a insegurança alimentar e nutricional da população brasileira (ABRINQ, 2004).

\subsection{IMPORTÂNCIA DO ACOMPANHAMENTO DO CRESCIMENTO E DESENVOLVIMENTO DO PRÉ-ESCOLAR E AS NECESSIDADES ENERGÉTICAS}

As populações de pré-escolares ( 0 a 6 anos) e escolares (7 a 12 anos) se encontram em fase vulnerável fisicamente, necessitando, portanto, de ênfase no acompanhamento nutricional. A transmissão de informações para essas duas faixas etárias se dá de forma eficaz, já que ambos os grupos estão em fase de formação de hábitos alimentares. Ferramentas lúdicas de apoio como materiais audiovisuais auxiliam na adequação da linguagem ao público infantil (FORATO, ARAÚJO, QUEIROZ, COELHO, BITENCOURT, 1999).

A avaliação do estado nutricional tem por objetivo verificar o crescimento e as proporções corporais em indivíduos ou em comunidades por meio da utilização de medidas antropométricas que são de grande importância tanto no diagnóstico precoce como na identificação do período em que ocorreu o déficit nutricional, seja em relação a perda de peso ou diminuição da velocidade de crescimento para aplicação de medidas preventivas. O uso de índices antropométricos tem sido uma estratégia válida para gerar indicadores sensíveis do estado nutricional, tendo como objetivo determinar a massa corporal, expressa pelo peso; as dimensões lineares, especialmente a estatura; e a composição corporal (a gordura subcutânea e a massa muscular). Seus resultados via de regra podem refletir, também, a condição de vida dos grupos populacionais estudados. Porém o perfil antropométrico de grupos populacionais de baixa renda que freqüentam instituições parece ser menos deficitário do que daqueles que não freqüentam (SANTOS, OLIVA E AMÂNCIO, 2006)

A alimentação desempenha um papel decisivo para o crescimento e o desenvolvimento físico da criança em idade pré-escolar, época em que ela passa por um acelerado processo de 
maturação biológica, juntamente com o desenvolvimento social e psicomotor, para o qual a participação família e da comunidade são fundamentais Também no aspecto sociocultural , a alimentação aprendida na infância poderá influenciar seu comportamento em relação a hábitos de saúde na idade adulta. Assim, é muito importante o modo como as refeições são conduzidas, tanto na qualidade como na quantidade de alimentos oferecidos, bem como no ambiente físico e emocional que os adultos proporcionam às crianças (HOLLAND, 1999).

A faixa etária do pré-escolar compreende a idade de 02 a 06 anos, apesar dos fatores biológicos e sociais e psicomotores, nesta idade a criança tem um ritmo de crescimento regular e ponderado para ambos os sexos. Somente a partir da idade pré-pubertária o sexo da criança irá interferir tanto em seu crescimento quanto em sua alimentação, processo mais comumente conhecido como estirão do crescimento.

As medidas antropométricas constituem o melhor método para avaliação nutricional de um grupo, sendo um espelho de sua situação alimentar. Essas medidas são normalmente comparadas a uma referência padrão. Por recomendação da OMS, é habitualmente adotada a referência do NCHS (National Center of Health and Statistics), também utilizada pelo Ministério da Saúde para a população brasileira (HOLLAND, 1999).

O trabalho realizado por DAVIES, GREGORY e WHITE (1995), comparando o gasto energético de crianças de 1,5 ano a 4,5 anos de idade, com as recomendações da FAO/WHO 85, conclui que estas recomendações são $10 \%$ e $12 \%$ mais altas para meninos e meninas, respectivamente. Os gastos energéticos foram de 1207 e 1301 calorias para meninos de 2,5 até 3,5 anos, e de 3,5 até 4,5 anos, respectivamente. Para as meninas, os gastos calóricos foram de 1125 e 1264 calorias para as mesmas faixas de idade mencionadas.

SZARFARC e cols.(1994), propuseram a utilização de curvas padronizadas para avaliar a adequação de consumo energético de crianças de 0 a 6 anos. Essas curvas foram construídas com valores obtidos pela multiplicação dos pesos de crianças de uma população com referência do NCHS, distribuídos por percentis, pelo número de unidades de energia indicadas para elas. Essas curvas permitem localizar, para cada idade, a necessidade de energia de crianças com peso nos 
percentis 3,10 , 50, e 90, que são os limites para se identificar desnutrição severa, moderada, peso mediano (normalmente usado para avaliar a adequação de consumo), e o limite entre peso normal máximo e obesidade. A partir dessas curvas, verificam-se as necessidades energéticas para meninos e meninas, sendo a variação determinada pelos percentis de peso e idade em meses. As curvas oferecem vantagens sobre os demais métodos por apontarem as necessidades individuais com sensibilidade e especificidade, e não as necessidades médias de um grupo populacional.

As necessidades nutricionais dos pré-escolares são determinadas pelo metabolismo basal, pelo ritmo de seu crescimento corporal levando-se em conta seu peso e sua altura, pelo nível e freqüência das atividades físicas e de repouso praticadas, e também pelo clima em que vivem, além do componente hereditário. A determinação das necessidades energéticas é primordial, sendo as dos demais nutrientes proporcionais a esse valor. Há vários estudos realizados na tentativa de se aproximar o valor real das necessidades energéticas dos pré-escolares. Quando se determina o valor energético do lanche escolar, deve-se considerar o tempo de permanência da criança na escola. Aquelas que permanecem de 4 a 7 horas por dia, deve receber 1/3 das recomendações nutricionais diárias, enquanto que a permanência de 8 horas ou mais, exige um total de pelo menos metade a até 2/3 dessas recomendações (HOLLAND,1999).

Programas de educação em saúde devem ser implementados nas escolas ou na comunidade, não se restringindo em fornecer apenas os conceitos sobre nutrição. É necessário ajustá-los de acordo com os recursos e a formação cultural da região. A vivência de práticas de saúde devem ocorrer pela valorização da qualidade dos alimentos durante as refeições, na merenda ou cantinas escolares, além da conscientização das conseqüências de uma alimentação inadequada para o indivíduo. Para um programa de educação nutricional ser bem-sucedido é essencial que seja efetivado no dia a dia do estudante. Assim, a adoção de um comportamento alimentar saudável do pré-escolar e escolar pode ser apontada como importante medida de promoção da saúde, com repercussões positivas na vida adulta (NEVES, 2005).

A alimentação da criança sofre grande influencia das pessoas com as quais convivem, tanto no âmbito familiar, quanto na escola. É importante o desenvolvimento de bons hábitos alimentares e da prática de atividade física adequada desde a infância. O período pré-escolar é 
muito importante, porque as condições de saúde da criança, nesta fase, refletem nos anos seguintes. O pré-escolar subnutrido será um escolar apático, fisicamente doente e desajustado socialmente, caso não seja feita uma intervenção nutricional em tempo hábil. O ideal é um candidato entrar na escola fisicamente sadio, moralmente alerta e socialmente ajustado (FORATO, ARAÚJO, QUEIROZ, COELHO, BITENCOURT, 1999).

As refeições do pré-escolar e do escolar são muito semelhantes às do adulto, constituindo basicamente de desejum, lanche, almoço, lanche e jantar. Para que o processo da nutrição seja eficiente, é preciso que a criança tenha uma alimentação adequada, tanto em qualidade quanto em quantidade. Essa alimentação deverá ser bem aceita pela criança, ingerida, retida no estomago, digerida e absorvida e metabolisada. Os detritos metabólicos, também, deverão ser eliminados pelas vias adequadas e sem perdas anormais de substanciais nutritivas. É necessário ainda um ambiente psicológico favorável. Basta não ser preenchido um único desses itens e carências nutricionais poderão se desenvolver (FORATO, ARAÚJO, QUEIROZ, COELHO, BITENCOURT, 1999).

\subsection{O DESENVOLVIMENTO DAS ESCOLHAS ALIMENTARES EM CRIANÇAS E ADOLESCENTES}

Quando crianças, o ato de comer e a hora das refeições têm um valor simbólico muito forte em nossa mente. E através da comida que absorvemos as primeiras noções de desejo e satisfação, recompensa e castigo, controle e disciplina. Na mesa de refeições aprendemos um pouco sobre quem somos, o que queremos e como obter; é um lugar onde também se aprende a regatear e negociar algum alimento a mais, ou alguma troca. Inclusive essas ocasiões são oportunidades de se aprender limites, compartilhar, consideração, esperar a vez e a arte de conversar, enfim, sobre boas maneiras. Dar a oportunidade da criança escolher a quantidade de alimentos que ela irá comer, estamos ajudando-a, a estabelecer um forte alicerce de autonomia e auto-regulação. Essas duas características são fundamentais para hábitos alimentares saudáveis. Muitas vezes as crianças são influenciadas positivamente por histórias em que o herói ingere 
determinado alimento, ficando forte e valente, fazendo com que a criança o adote, sendo eventualmente uma interessante estratégia, quando bem conduzida. (HOLLAND, 1999).

A criança pequena come quando se sente fome, porém, na idade escolar,o ato de se alimentar se torna muito mais complexo, envolvendo fatores de ordem fisiológica, psicológica, social e cultural. A chave para uma dieta saudável está na busca por uma abordagem balanceada dos alimentos (MS, 2002).

O comportamento alimentar ocupa um papel central na prevenção e tratamento da obesidade e da desnutrição. Na promoção de uma alimentação saudável dois aspectos não devem ser esquecidos: a mudança do comportamento alimentar é um objetivo com elevada taxa de insucesso na idade adulta, e ao contrário, o sucesso de um comportamento alimentar adequado está claramente relacionado com os hábitos alimentares aprendidos na infância. Estes dois fatos apontam para que a intervenção na promoção de comportamentos alimentares saudáveis deverá incidir fortemente nos primeiros anos de vida, de modo a criar desde início comportamentos saudáveis que tenderão a persistir ao longo da vida (ANDRADE, 2005).

A formação de hábitos ou gostos alimentares nas diferentes culturas, o status, o prestígio, a pressão publicitária, o aspecto religioso, enfim são inúmeros os aspectos que orientam as escolhas alimentares. Um importante aspecto do padrão alimentar ocidental relaciona-se com o fast-food que é o principal fenômeno de consumo no mundo moderno, onde a carne aparece como o alimento de maior prestígio no ocidente. O sanduíche e os refrigerantes ganham preferência quando o mais importante é a praticidade e a rapidez. A publicidade e a ideologia do consumo favorecem a formação de novos hábitos inimagináveis há pouco mais de três décadas (BLEIL, 1998).

\section{Determinantes Orgânicos e Cognitivos no Desenvolvimento das Preferências}

\section{Alimentares.}

As preferências alimentares nos primeiros meses de vida envolvem mecanismos inatos que, desde cedo, são influenciados por processos de aprendizagem. A criança recém-nascida, por 
exemplo, apresenta preferência por sabores doces, e um pouco mais tarde também por alimentos salgados. Contudo a preferência pelo salgado vai diminuindo por volta dos 6 meses, desde que a criança não seja exposta a alimentos com teor de sódio elevado, revelando-se assim desde cedo a influência da exposição aos alimentos na aquisição dos hábitos alimentares (...) Os resultados apresentados apontam para a existência de mecanismos fisiológicos inatos determinantes das preferências e hábitos alimentares preferência por doce e salgado, aversão a novos alimentos e sistemas de auto-regulação que, contudo, são fortemente influenciados por fatores ambientais (...) Desde cedo estão presentes sistemas de auto-regulação alimentar, que permitem à criança optar por quantidades e tipos de alimentos de modo a manter o equilíbrio nutricional. A maioria das crianças terá a capacidade de regular "inteligentemente” a ingestão de nutrientes, desde que lhes seja disponibilizado uma variedade de alimentos. Contudo, nem todas as crianças parecem utilizar de igual modo esta capacidade. Jonhson e Birch (1994) identificaram que as crianças com mais reservas corporais de gordura fazem uma utilização mais deficiente dos sistemas de autoregulação. O controle exercido pelos pais durante a alimentação, como por exemplo obrigar a criança a ingerir uma quantidade ou qualidade de alimentos, ou a comer todos os alimentos que tem no prato, revela-se inversamente correlacionado com a capacidade de auto-regulação, indicando que este estilo parental levará as crianças a substituir os sinais fisiológicos por estímulos externos na regulação alimentar (ANDRADE, 2005).

A importância da percepção de controle sobre o ambiente alimentar, que apresentou a correlação mais elevada com a menor ingestão de gorduras, aponta para a necessidade das crianças terem liberdade de escolha no seu ambiente alimentar e aprenderem a tomar decisões adequadas em oposição a estratégias de controlo parental. Contudo os autores relativizam esta conclusão considerando que as crianças com comportamentos alimentares mais saudáveis poderão ser aquelas a quem é dada maior liberdade de decisão pelos pais, sendo assim o controlo uma conseqüência do comportamento alimentar saudável e não um fator determinante (ANDRADE, 2005). 


\section{Determinantes Ambientais Relacionados aos Fatores Psicossociais e Econômicos}

A disponibilidade e acessibilidade de alimentos são pistas utilizadas pelas crianças para iniciar um comportamento alimentar e são determinantes na aquisição de preferências, podendo ter mais peso no hábito de consumo de determinados alimentos do que o sabor. A apresentação de alimentos variados é também essencial para a aquisição de uma dieta variada, o que constitui uma das premissas fundamentais para uma alimentação saudável. A exposição a vegetais e fruta é determinante não só do consumo mas também da preferência por este tipo de alimentos. Parece claro que, a familiaridade com determinados alimentos, promove não só o seu consumo, mas também a aquisição de preferências alimentares (ANDRADE, 2005).

Considerando as múltiplas substâncias naturais - minerais, vegetais e animais, as quais podem potencialmente, servir de alimento e são colocadas pela natureza a disposição dos homens, observa-se a utilização de um numero pequeno delas. Esta seleção pode, talvez, ser objeto de análise em termo de performances adaptativas, mas não se pode reduzir somente a isto. Ela se articula com as representações simbólicas que revelam a arbitrariedade das culturas e, sobretudo, participam da diferenciação cultural dos grupos sociais, pois as escolhas as escolhas são diferentes de uma cultura para outra. A decisão sobre o que se come é, portanto, a escolha operada pelo grupo humano no interior do conjunto de produtos vegetais e animais colocada à sua disposição pelo meio natural, ou que poderá ser implantada pela decisão do grupo (POULAIN E PROENÇA, 2003).

As diferenças culturais, principal responsável pelas escolhas alimentares de um grupo, precisam ser analisadas com critério. Uma vez que, as culturas de várias nações se misturam, a pressão da industria alimentícia, mídia e da própria sociedade exigem que a escolha individual seja a mesma do grupo, deixando mais uma vez, inúmeras possibilidades de escolha ignoradas.

A imersão de uma criança no contexto alimentar é pontuada por ritmos; o uso de certos produtos relaciona-se com o biológico tanto no tocante à expressão de determinados fenótipos quanto na ativação de mecanismos de regulação e de controle da tomada alimentar. A alimentação é a primeira aprendizagem social do pequeno homem. Ela está no centro do processo 
de “socialização primária”. O comportamento alimentar de uma criança entrando em um mundo largamente submetido a condicionantes fisiológicas, à alternância de sensações de fome aos comportamentos desencadeados por essas sensações (apelos, choros, gritos... depois leite) e sensações de saciedade e de abundância que se seguem. Os mecanismos biológicos que regulam certos padrões sociais, como as alternâncias de repouso e trabalho são a primeira influência social. Depois com o desmame, o aprendizado da alimentação “normal” desenvolverá o gosto da criança, ensinando-lhe a amar aquilo que é bom na sua cultura, e regulará sua mecânica digestiva aos ritmos da sociedade (ANDRADE, 2005).

A alimentação se inscreve dentro de uma série de ciclos temporais socialmente determinados como ciclo de vida dos homens. Assim, tem-se uma alimentação de lactente, de criança, de adolescente, de adulto e de idoso. Cada etapa corresponde á estilos alimentares, compreendendo os alimentos autorizados e os proibidos, os ritmos das refeições, os status dos comensais, os papeis, as condicionantes, as obrigações e os direitos. Representam tempos que vão se alternando ciclicamente, variando conforme o ritmo das estações e dos trabalhos no campo pelos agricultores, o da migração das caças pelos caçadores, a alternância de períodos de abundância e penúria - sejam eles naturais ou decididos pelo homem, como por exemplo, períodos festivos onde todos os alimentos são autorizados e de períodos de jejum parcial ou total. Enfim, é um ritmo cotidiano, com suas alternâncias de tempos de trabalho e de repouso, as diferenças das refeições, as comidas fora das refeições e sua implantação horária respectiva (POULAIN E PROENÇA, 2003).

O conceito de alimentação saudável é amplo e abrange desde o aporte adequado de nutrientes para promover o crescimento e desenvolvimento ideal até os cuidados de prevenção de alguns problemas mórbidos que aparecem na idade adulta cuja etiologia e prognóstico podem estar relacionados, pelo menos em parte, à alimentação e hábitos alimentares dos primeiros anos de vida da criança. Esta alimentação adequada deve respeitar os padrões sociais, econômicos e culturais da família e mesmo da região, além da competência digestiva, absortiva e metabólica da criança, levando em consideração as necessidades nutricionais de cada idade (NEVES, 2005).

Sendo a alimentação uma necessidade biológica básica, que ocorre em ambiente social, comumente na família, observamos que circunstâncias como o desenvolvimento de novos 
sistemas de vida nas zonas urbanas, a incorporação da mulher como força de trabalho, as distâncias dos locais de trabalho, a relativa facilidade para a aquisição de alimentos processados e o efeito da propaganda sobre a alimentação são fatores que têm contribuído para a deterioração das relações familiares e têm modificado o ambiente social onde se consome o alimento. Essas circunstâncias e a intenção de copiar modelos indesejáveis de consumo têm levado ao abandono de costumes e de componentes tradicionais importantes na dieta. Naturalmente, o pré-escolar vai sofrer essas influências dentro do ambiente em que vive, pois sua família não está dissociada desse coletivo (HOLLAND,1999).

Para uma alimentação saudável é essencial que a criança possua acesso a produtos saudáveis. Devem ser considerados os cuidados com a preparação do alimento tanto do ponto de vista nutricional como das condições higiênico-sanitárias. A família, a escola e a sociedade têm a responsabilidade de favorecer a adoção de um comportamento adequado por parte das crianças, que devem ser capazes de encontrar equilíbrio alimentar para alcançar uma boa qualidade de vida. Aos profissionais de saúde cabe, além do acompanhamento, orientação quanto ao preparo e higiene dos alimentos, a avaliação da alimentação sobre o crescimento e desenvolvimento do escolar e sua participação em programas educativos sobre nutrição, seja nas escolas ou na comunidade. O grau de educação da família, sua condição social e econômica tem efeitos consideráveis sobre o modo de vida e hábitos alimentares da criança (NEVES, 2005).

\section{Impacto da Publicidade de Alimentos em Pré-Escolares e Escolares}

Presente em aproximadamente 40 milhões de casa, a televisão é o veículo de maior peso no Brasil e o segundo eletrodoméstico mais presente nos lares, perdendo apenas para o fogão (INMETRO e IDEC, 2002). A televisão é o veículo de comunicação utilizado para o entretenimento e para a educação e representa a maior fonte de informação sobre o mundo, sendo capaz de transmitir aos mais diversos lugares e culturas dados sobre como as pessoas se comportam, o que vestem, o que pensam, como aparentam ser e o que comem (ALMEIDA, NASCIMENTO E QUAIOTI, 2002). 
A televisão chegou a ser definida como “a caixinha de distração e da destruição”, por ser, de um lado, um canal informativo e uma opção barata de lazer, e, por outro, algo que manipula, distorce a realidade e é um convite à passividade, e à acomodação (INMETRO e IDEC, 2002).

Nota-se significativo aumento do tempo gasto com o hábito de assistir à TV. No Brasil, adolescentes passam cerca de cinco horas por dia diante da TV. Sabe-se que uma exposição de apenas 30 segundos a comerciais de alimentos é capaz de influenciar a escolha de crianças a determinado produto, o que mostra que o papel da TV, na construção de hábitos alimentares, deve ser investigado. Diante da TV, uma criança pode aprender concepções incorretas sobre o que é um alimento saudável, uma vez que a maioria dos alimentos veiculados possui elevados teores de gorduras, óleos, açúcares e sal. Maus hábitos alimentares estão associados a diversos prejuízos à saúde, entre eles, a obesidade, cujos índices têm crescido nas últimas décadas como resultado de aumento no consumo de alimentos com alta densidade calórica e redução na atividade física. Há demonstrações de que, entre outros diversos fatores, o tempo que um adolescente passa assistindo à TV pode estar associado à obesidade, pois cada hora diante da TV pode resultar em aumento de até $2 \%$ em sua prevalência (ALMEIDA, NASCIMENTO E QUAIOTI, 2002).

Cerca de 50\% de crianças entre 8-13 anos assistem mais de 15 horas de TV por semana (segunda a sexta de 15 horas de TV por semana e mais 6 horas aos sábados e domingo), 1/3 dessas crianças se alimentam diante da TV diariamente, 60\% não praticam atividades esportivas, 30\% têm sobrepeso - percentil >85 e 13\% são obesos- percentil >95 (ALMEIDA, 2003).

As crianças e os jovens são geralmente muito vulneráveis à publicidade, porque não têm uma mentalidade crítica nem a capacidade de ler a verdadeira mensagem que uma determinada publicidade sta transmitindo. (...) Segundo Sérgio Capparelli, o publico infantil entre 1 e 14 anos é responsável por uma boa parte do consumo de iogurtes, refrigerantes, achocolatados, chicletes de bola, roupas e brinquedos. Além de criar hábitos inadequados, a publicidade pode causar problemas de saúde nas crianças, por veicular produtos com excesso de gordura, sal e açúcares. A obesidade é uma doença de âmbito mundial, que se caracteriza por excesso de gordura e peso 
20\% acima do ideal para altura, o sexo e a idade, podendo acarretar outros problemas de saúde, como pressão alta, doenças cardíacas, problemas nos dentes, etc.(INMETRO e IDEC, 2002).

A industria alimentícia faz forte investimento na divulgação de produtos de alto teor calórico para crianças e adolescentes, que tendem a se manter fiéis a esses hábitos de consumo. Embora sejam alimentos potencialmente causadores de obesidade, esses produtos surgem nas propagandas associadas a saúde, beleza, bem-estar, juventude, energia e prazer. (...) Os brasileiros nascidos após os anos 80 estão mais expostos aos efeitos nocivos da transição nutricional e publicidade de alimentos não regulamentada, e por isso tem maior chance de apresentar doenças associadas a obesidade e ao sedentarismo, como hipertensão, diabetes, infarto, acidente vascular cerebral, câncer de intestino e de mama (LOPEZ E TADDEI, 2005).

Muitos produtos, serviços ou idéias aparecem na televisão por meio de merchandising. A situação se torna mais grave quando apresentadoras famosas de programas infantis, como Xuxa, Angélica, Eliana, etc recomendam esses produtos às crianças, influenciando atitudes e gostos, criando falsas necessidades e estimulando o consumo. Ao assistir a programas infantis as crianças assimilam muitos anúncios dos grandes anunciantes: Coca-cola, Yakult, Glub-Glub, Iogurte (PAULISTA), gelatina (FLOKIN), cereais matinais (KELLOG’S), Snowflakes da Nestlé, Nissin Lamen, achocolatado (NESCAU E GALAK), entre outros. Só para ter uma idéia, os gastos feitos em publicidade de produtos alimentícios voltados para o público infantil somaram o equivalente a US\$185,3 milhões, em 1996 (INMETRO e IDEC, 2002).

O aumento de consumo de refrigerantes e embutidos, que tem marketing muito agressivo, ou mesmo dos laticínios, que, além da propaganda maciça, também tiveram redução de preço nos últimos anos, permite dizer que a propaganda, aliada ao bom preço, tem sido eficaz na mudança de hábitos do brasileiro. A margem do consumo durante décadas, alguns setores mais pobres estão exercendo seu poder de compra, talvez buscando para além da praticidade, o status que estes produtos industrializados lhes fornece. Outra revelação deste estudo é que o brasileiro das grandes cidades está seguindo a tendência mundial, que para alguns pode ser chamada "padrão americano”, traduzida em comer mais, aumentar a proporção da gordura ingerida a adotar o habito de comer fora de casa. Em relação a utilização de refeições rápidas, só nesta década, esse 
mercado cresceu 30\%. O problema pode ser ainda maior, considerando que cada vez mais o fast food invade também os lares brasileiros (BLEIL, 1998). A imitação da cultura alimentar americana já se provou prejudicial a saúde humana não só a longo prazo, mas também de forma imediata.

A obesidade torna-se um problema de saúde pública agravado pelo fato de a TV exercer grande influência sobre os hábitos alimentares e promover o sedentarismo. Conhecer como os meios de comunicação influenciam o estilo de vida e, principalmente, o comportamento alimentar é essencial na tarefa de educar, informar e aconselhar os pais a respeito da influência da TV nas escolhas alimentares de seus filhos, além de dar subsídios para elaboração de estratégias de intervenção contra sua disseminação.

A influência da publicidade nos hábitos alimentares dependerá dos pais cederem ou não aos pedidos das crianças, embora este papel mediador diminua com o desenvolvimento da autonomia da criança e do adolescente (ANDRADE, 2005).

As preferências alimentares na sociedade moderna estão cada vez mais influenciadas pela publicidade. É interessante assinalar que o significado dos alimentos vai ser elaborado principalmente no ato da sua transformação e do seu consumo. No que concerne a sua produção poucos significados serão incorporados. A industria tem sido eficaz nesta função, qual seja, a de outorgar símbolos a tudo que produz. Muitas vezes o que tem valor simbólico pode trazer prejuízos: é gostoso mais não tem valor nutricional. Pode-se usar a coca-cola como exemplo de como a mídia tem condicionado as preferenciais do consumidor (BLEIL, 1998).

\section{Aprendizagem por Condicionamento}

Os processos de aprendizagem por condicionamento parecem ter um papel nem sempre linear na aquisição de hábitos e preferências alimentares. As conseqüências fisiológicas da ingestão do alimento geram uma aprendizagem de preferências alimentares por associação. Este processo será particularmente pertinente para explicar a preferência das crianças por alimentos com elevada densidade calórica. Segundo Birch e Fisher (1998) esta preferência não é inata, e 
resultará da associação dos sabores deste tipo de alimentos aos efeitos fisiológicos de saciedade, resultantes da digestão e absorção. Crianças que têm grande acessibilidade a estes alimentos terão mais oportunidades de consumo e conseqüentemente de aprendizagem associativa, gerando-se uma preferência bastante forte por alimentos muito calóricos (ANDRADE, 2005).

Segundo o mesmo autor, o reforço da ingestão de um determinado alimento que a criança não gosta poderá levá-la a criar uma aversão maior pelo alimento. A prática de reforço com alimentos agradáveis, com o intuito de aumentar a preferência por alimentos saudáveis de que a criança não gosta, parece ter o efeito exatamente oposto: aumenta a preferência pelo alimento usado como reforço (geralmente rico em calorias) e intensifica a aversão pelo alimento saudável. É indispensável considerar estes resultados pelos profissionais de saúde tanto na elaboração de programas comportamentais como na informação dada aos pais. Os programas comportamentais deverão ser utilizados mas sempre com a preocupação de fomentar uma atitude positiva em relação aos alimentos que a criança deverá comer em maior quantidade e não potencializar a aprendizagem de preferências por alimentos a consumir mais raramente (...) O papel dos pais como modelos de comportamentos alimentares das crianças está amplamente documentado, assim como a contribuição da modelagem parental no tratamento da obesidade. Os estilos parentais têm sido considerados como um fator importante na aquisição de preferências alimentares. Os pais que tendem a influenciar o comportamento alimentar dos filhos pressionando-os a comer certo tipo ou quantidade de alimentos tendem a ter piores resultados do que aqueles que utilizam a modelagem com estratégia preferencial. Nos pais que optam pelo estilo controle é freqüente a crença de que restringir ou proibir um determinado alimento evita a preferência pelo mesmo. Contudo, o que acontece é exatamente o contrário: a proibição aumenta a motivação pelo alimento (...) Como já foi referido um controlo parental excessivo também reduz a eficácia dos sistemas de auto-regulação. O papel dos pais será então de criar acessibilidade a uma variedade de alimentos maioritariamente saudáveis e permitir que a criança escolha o quanto e o que quer comer, sendo eles próprios modelos de uma alimentação saudável. O conhecimento dos obstáculos parentais à concretização de uma alimentação saudável é um campo enriquecedor, principalmente se as ações de educação alimentar apresentarem soluções para problemas específicos à população a que se destinam 
São inúmeras as razões que envolvem a escolha dos alimentos. Muitas vezes estão em jogo, ao mesmo tempo, mais de um fator até a decisão final. Segundo Igor de Garine, apesar de percebermos como óbvias muitas relações entre a comida, nutrição e fatores culturais, até hoje não se precisou às regras que regem os comportamentos alimentares, o que não se revela uma tarefa facilmente atingível no curto prazo. A escolha do alimento revela muitas vezes a que grupo se deseja pertencer, seja este social, étnico ou de idade (BLEIL, 1998).

As escolhas alimentares também são experiências aprendidas, a familiaridade com o alimento é o fator principal para a aceitação ou rejeição, e aprende-se a gostar do que está disponível (HOLLAND, 1999).

\subsection{EDUCAÇÃO ALIMENTAR E NUTRICIONAL}

O processo de educação nutricional pode ser definido como um complexo conjunto de atividades que visa à formação de hábitos alimentares saudáveis, isto implica em uma enorme mudança na forma de pensar e agir dos indivíduos, mudanças estas, completamente vinculadas às suas praticas e atitudes diárias (GOUVEIA, 1998).

Diante do aumento das prevalências de obesidade e doenças crônicas degenerativas, torna-se urgente estudar estratégias que permitam o seu controle. As práticas alimentares são destacadas como determinantes diretos dessa doença e a educação nutricional tem sido abordada como tática a ser seguida para que a população tenha uma alimentação mais saudável e, dessa forma, um peso adequado (TRICHES E GIUGLIANI, 2005) .

Entende-se como práticas alimentares, o conjunto de ações ligadas ao ato de comer, desde a escolha e presença de determinados alimentos, com suas variações de qualidade, quantidade e freqüência, bem como os tipos de preparações e as temperaturas servidas, como também o ambiente físico e emocional do local de refeição, o que inclui as interações sociais e psicológicas entre crianças e adultos, em toda sua extensão (HOLLAND,1999). 
Os estudos que têm avaliado associações da obesidade com o nível de conhecimento de nutrição e com as práticas alimentares em escolares são escassos. O estudo de TRICHES E GIUGLIANI (2005) revelou que: quanto aos conhecimentos em aspectos sobre nutrição, 90,8\% das crianças responderam corretamente às questões sobre alimentos fontes de vitaminas e minerais, $23,4 \%$ às questões sobre alimentos mais saudáveis, $19 \%$ às questões sobre alimentos mais ricos em gordura, $25,8 \%$ às questões sobre alimentos fonte de fibras e $4,9 \%$ às questões sobre alimentos que promovem mais energia ao corpo (...) A interação entre prática alimentar e nível de conhecimento em nutrição mostrou-se altamente associada com a obesidade, indicando que as crianças com menos conhecimentos e práticas alimentares menos saudáveis tiveram cinco vezes mais chances de serem obesas (...) Outro fator implicado no aumento das prevalências de obesidade é a recente e excessiva comercialização de variedade de alimentos ricos em energia e gorduras, a disposição dos escolares. Por outro lado, alimentos como hortaliças e frutas, com menor densidade energética e mais nutritivos, estão cada vez menos presentes na dieta infantil.

TRICHES, (2005), relata ainda que, crianças com menos conhecimentos relatem suas práticas alimentares de forma mais acurada e fidedigna. Aquelas com mais conhecimentos podem relatar práticas que elas sabem ser mais saudáveis, mas que, não necessariamente são as praticadas. As crianças têm poucos conhecimentos em nutrição e hábitos alimentares, evidenciando que as escolas, os pais e a mídia têm veiculado mensagens insuficientes e ineficazes de hábitos alimentares mais saudáveis. A relação entre conhecimentos em nutrição e estado nutricional sugere que outros fatores, como falta de ambiente favorável na praticabilidade das intenções de melhorar a qualidade da dieta, são fundamentais para modificar o estado nutricional ou prevenir a obesidade. As intervenções, portanto, devem ir muito além de apenas promover conhecimentos nutricionais. São necessárias ações integradas que visem à saúde das crianças, envolvendo famílias, escolas, comunidades e industria alimentícia. Os estudos que têm avaliado associações da obesidade com o nível de conhecimento de nutrição e com as práticas alimentares em escolares são escassos.

Seria desejável que a sociedade brasileira iniciasse atividades de educação junto a préescolares e escolares, utilizando os meios de comunicação e os currículos escolares para conscientiza as novas gerações da importância da alimentação correta (LOPEZ, TADDEI, 2005). 
Afinal, a simples proibição de alimentos industrializados ou com altos teores de açúcar e gordura saturada nas cantinas escolares sem o devido esclarecimento convincente, além de ações de educação nutricional e incentivo ao consumo de novos alimentos, não é eficiente.

Na maioria das escolas particulares, que não servem a merenda tradicional das escolas publicas, as cantinas vendem produtos industrializados que colaboram para uma alimentação artificial e de baixo valor nutricional. Paralelamente, os pais com pouco tempo para organizar o lanche das crianças, optam por produtos industrializados, que dispensam preparo. Dessa forma o lanche caseiro ficou "fora de moda," uma questão cultural que faz com que as crianças sintam vergonha de comer alimentos naturais (TAGLIARI, 2002).

O tema nutrição e alimentação nas escolas têm como objetivo principal despertar uma consciência crítica a cerca da necessidade de se buscar melhores escolhas alimentares, ou até mesmo de tentar mudanças em hábitos alimentares voltados para uma dieta industrializadas procurando com isto uma alimentação mais natural (BORSARI, CRUZ, LOLLI, OLIVEIRA E SANTOS, 2005).

Uma alimentação mais saudável e nutritiva para as crianças, com a introdução de novos hábitos alimentares, educação e proteção ambiental, valorização da produção regional e resgate da cultura do meio rural são algumas das vantagens de programas que priorizam o alimento orgânico na merenda escolar. Alguns estados do sul do Brasil já apresentam experiências que mostram que introduzir a alimentação orgânica na merenda escolar pode ser uma excelente alternativa de mercado institucional, fortalecendo a economia local, com aumento de arrecadação, maior quantidade de dinheiro circulando na comunidade, criação de novos empregos e viabilização da produção familiar. O lanche escolar preparado com alimentos orgânicos pode partir de uma iniciativa da própria escola, que pode incluir em suas atividades, a construção de uma horta dentro dos seus limites. Deste modo ela estará ensinando ao aluno, não só a como se alimentar melhor, mas também, produzir o seu próprio alimento (TAGLIARI, 2002).

A educação nutricional tem grande importância no esclarecimento de toda população, inclusive da criança em suas escolhas alimentares, mas principalmente na orientação dos pais. 
Infelizmente, conhecimentos na área de nutrição não são obrigatórios para professores e nem pessoas que trabalham na cozinha ou cantinas escolares. Muitas vezes o trabalho de educação nutricional fica defasado, em alguns casos inexistente. Por falta da educação nutricional, a criança deixa de ingerir alimentos importantes para a sua saúde e crescimento (NEVES, 2005).

A escola deve atuar no sentido de transformar os meios de comunicação em aliados do processo educativo dos alunos. Garantindo o acesso aos meios de comunicação, a escola poderá desenvolver trabalhos que irão refletir sobre as técnicas e as estratégias da mídia. Se for bem sucedida, despertará a consciência crítica dos alunos-espectadores com o intuito de torná-los agentes da comunicação. "Educar com e por meio do rádio, da TV, do jornal, do computador e de todo e qualquer recurso ou veículo de comunicação passa a ser, hoje, questão de exercício e de prática de direitos de cidadania” (INMETRO e IDEC, 2202).

O trabalho de transmissão de informações em nutrição deverá se estender aos adultos que trabalham com educação infantil e àqueles que atuam diretamente com a alimentação de crianças. O sistema de trabalho em cascata é adequado nesses casos, já que o treinamento de alguns professores, com o apoio de profissionais especializados em nutrição e saúde, poderá beneficiar de centenas de crianças com conhecimentos básicos na área supracitada. Através da instrumentalização de professores que trabalham com a educação infantil, permitindo uma melhoria nas escolhas alimentares destes e de suas famílias (FORATO, ARAÚJO, QUEIROZ, COELHO, BITENCOURT, 1999).

Em vista da grande variação diária da alimentação e da rápida mudança dos hábitos alimentares infantis, o desenvolvimento de instrumentos capazes de medir com exatidão a dieta habitual das crianças apresenta-se como um importante desafio metodológico. Além disso, deve-se considerar a limitada capacidade cognitiva deste grupo, o que faz com que a informação dietética deva ser obtida com os adultos responsáveis pela criança, em casa, ou na escola (COLUCCI, PHILIPPI E SLATER, 2004). Isso, se ignorarmos que em muitos casos os pais desconhecem o que consta da alimentação dos filhos, 


\section{pois são as empregadas, secretárias, etc que cuidam da alimentação destas mesmas crianças.}

Para promover hábitos alimentares mais saudáveis, e, conseqüentemente, e melhorar a saúde nutricional das crianças, acredita-se que seja importante que as pessoas envolvidas no dia a dia criança tenham conhecimentos de alimentação e nutrição. Porém, estudos não encontraram diferenças significativas entre conhecimentos em nutrição de crianças e adolescentes obesos e eutróficos. Por outro lado, pesquisas que utilizaram educação nutricional como uma das estratégias de intervenção, relataram melhora nos conhecimentos nutricionais, atitudes e comportamento alimentar, influenciando também nos hábitos alimentares da família. As práticas alimentares menos saudáveis, quando levado em consideração, o nível de conhecimento em nutrição dos escolares, foram fortemente associadas à obesidade. Escolher ou elaborar um instrumento adequado não é tarefa fácil, já que as crianças são influenciadas pela sua habilidade cognitiva, seu status de peso e pela maneira como as perguntas são feitas. Além disso, suas práticas alimentares mudam rapidamente, são menos hábeis em recordar, estimar e cooperar em avaliações dietéticas (TRICHES E GIUGLIANI, 2005) .

Também é importante ressaltar que por maior que seja a influência da família e escola, a alimentação não se limita a este mundo, ela tem uma conexão com o mundo exterior, sendo um elo que determina como vemos e entendemos o mundo. No trabalho com crianças são consideradas uma série de valores sociais que vão sendo passados a elas no dia a dia, e que moldam seu caráter e sua personalidade. Durante as refeições, Há uma série de condutas esperadas, que devem ser ensinadas às crianças em seu devido tempo (HOLLAND, 1999).

A freqüência com que os pais demonstram hábitos alimentares saudáveis pode estar associada à ingestão alimentar e ter implicações de longo prazo sobre o desenvolvimento do comportamento alimentar dos filhos (DAVANÇO, TADDEI E GAGLIANONE, 2004).

Segundo o mesmo autor, o conhecimento, as atitudes, comportamentos e habilidades desenvolvidas por meio de efetivos programas de saúde em escolas, voltados para a 
conscientização de que a adoção de hábitos saudáveis trará melhor qualidade de vida, capacitam crianças e jovens para fazer escolhas corretas sobre comportamentos que promovem a saúde do indivíduo, família e comunidade. Por meio do trabalho nas preferências alimentares de crianças, que são determinantes importantes da ingestão alimentar, promove-se o balanceamento na composição da dieta em relação aos macronutrientes e ao total energético.

As propostas de inclusão dos temas de segurança alimentar nos projetos pedagógicos escolares, nos diferentes níveis de ensino, podem contribuir para a instrumentalização dos indivíduos, permitindo aos sujeitos "navegarem" nesse mar de informações. No entanto, é necessário aprofundar o "como" tais "inclusões" se concretizariam. Seria importante considerálas dentro das discussões político-filosóficas do ensino brasileiro, não reduzindo o tema à mera inclusão de conteúdos (SANTOS, 2005).

Compete aos educadores e/ou nutricionistas, desenvolver estratégias sistematizadas para impulsionar a cultura e valorização da alimentação, concebidos no reconhecimento da necessidade de respeitar, mas também modificar crenças, valores, atitudes, representações, práticas e relações sociais que se estabelecem em torno da alimentação. Visa-se o acesso econômico e social a uma alimentação quantitativa e qualitativamente adequada, que atenda aos objetivos de saúde, prazer e convívio social (PASQUA, JATOBÁ, CARDOSO, LIMONI, 2005).

A escola é um espaço privilegiado para a aprendizagem sobre alimentação e a nutrição como ciência, arte, técnica e história. As noções básicas de nutrição e saúde podem ser dadas integradas às atividades pedagógicas. A adoção de novos comportamentos pelas crianças resulta em benefício extensivo às famílias, que poderão reformular hábitos alimentares, dada a grande influencia exercida duplamente pela criança e pela escola. É nessa faixa etária que se desenvolvem o espírito de iniciativa, o aumento da destreza física e a aquisição de novas aptidões e habilidades. O desejo de conhecer, leva a criança a experimentar o mundo que a cerca, estimulando-a a usar os sentidos. É assim que ela descobre o gosto pelos alimentos que ela prepara ou pesquisa (FORATO, ARAÚJO, QUEIROZ, COELHO, BITENCOURT, 1999). 
A escola tem potencial para estimular a formação de hábitos alimentares adequados. Um programa educativo, além de promover modificações nos alimentos comercializados nas cantinas deve explicar o por que das alterações, deve incentivar a substituição e não apenas a proibição do consumo de determinados alimentos. Não existem alimentos proibidos e sim alimentos cujas quantidades devem ser controladas, afinal ter uma alimentação equilibrada pode e deve ser divertido, caso contrário quando o aluno estiver fora da escola com livre acesso aos alimentos “proibidos”, prejudicará os resultados da intervenção escolar (VIUNISKI, 2005).

Pequenas intervenções na escola, no sentido de melhorar o valor nutricional das refeições servidas por ela, tendem a ter um impacto positivo na prevenção de doenças melhorando a ingestão dietética das crianças (NOVAES et al., 2003).

Os momentos das refeições na escola são considerados como atividades pedagógicas de grande valor no aprendizado infantil. Nas refeições ocorre cotidiana e paulatinamente uma adaptação ao meio social adulto, transformando as crianças em função do conjunto de realidades coletivas, às quais a consciência comum atribui algum valor, o que comumente chamamos de boas maneiras. É também nesse meio social que a criança vai moldar suas preferências alimentares e sua capacidade de ingestão, o que ocorre entre 2 e 5 anos de idade. A formação de hábitos por alimentos gordurosos e doces com alta densidade de energia pode ser estabelecido na infância como padrão para a vida futura (HOLLAND,1999).

A alimentação e a capacidade da criança de converter esta alimentação em energia e em novos tecidos orgânicos influenciarão o estado de saúde, não só enquanto a criança, mas também na fase adulta. O comportamento alimentar desenvolvido nessa faixa etária irá constituir a base da alimentação futura, especialmente no que se refere a variedade dos alimentos escolhidos. É necessário que a criança adquira experiência em tomar decisões sobre a seleção alimentar. A escola pode ajudar a promover e a continuar hábitos alimentares adequados e a realização de refeições regulares. Um das formas de ajudar a criança a se alimentar de modo inteligente é convencê-la que a alimentação tem importância no seu crescimento e desenvolvimento (FORATO, ARAÚJO, QUEIROZ, COELHO, BITENCOURT, 1999). 
O comportamento alimentar tem suas bases fixadas na infância, transmitidas pela família e sustentadas por tradições. Porém, ao longo da vida, o comportamento alimentar pode vir a modificar-se em conseqüência de mudanças do meio, relativas à escolaridade ou relacionadas às mudanças psicológicas dos indivíduos. Os hábitos alimentares da população escolar estão determinados por uma série de fatores históricos, sociais, religiosos, econômicos e geográficos inerentes a cada comunidade. Sendo a escola ambiente propício para o processo educativo, o professor é o membro central da equipe de saúde escolar pois, além de ter maior contato com os alunos, está envolvido na realidade social e cultural de cada discente e possui uma similaridade comunicativa (DAVANÇO, TADDEI E GAGLIANONE, 2004).

O nutricionista, como o profissional de saúde que atua em todas as situações nas quais existam interações entre o homem e o alimento, pode exercer a sua função de promover a saúde na escola por meio de atividades assistenciais e educativas relacionadas com o desenvolvimento de um programa de alimentação escolar, integrando-se com os demais profissionais que atuam nesse espaço (COSTA, RIBEIRO E RIBEIRO, 2001). 


\section{POLÍTICAS PÚBLICAS DE ALIMENTAÇÃO E NUTRIÇÃo}

A promoção da saúde é definida pela Carta de Ottawa dentro dessa última concepção como "o processo de capacitação da comunidade para atuar na melhoria da sua qualidade de vida e saúde, incluindo uma maior participação no controle deste processo". A elaboração e implementação de políticas públicas saudáveis, a criação de ambientes favoráveis à saúde, o reforço da ação comunitária, o desenvolvimento de habilidades pessoais e a reorientação do sistema de saúde são os cinco principais campos de ações definidos na Carta de Ottawa. A partir do final dos anos 1990, o termo "promoção de práticas alimentares saudáveis" começa a marcar presença nos documentos oficiais brasileiros. Aliada à promoção de estilos de vida saudáveis, a promoção de práticas alimentares saudáveis se constitui uma estratégia de vital importância para o enfrentamento dos problemas alimentares e nutricionais do contexto atual. Segundo as Nações Unidas, promover exige que o Estado implemente políticas, programas e ações que possibilitem a progressiva realização do direito à alimentação, definindo, com isso, metas, recursos e indicadores para esse fim. Embora os documentos não deixem claro o que seria o seu conceito, a perspectiva apontada pelas Nações Unidas é que parece nortear as políticas no campo.

A instituição da Política Nacional de Alimentação e Nutrição (PNAN) pode ser considerada como uma das expressões que oficializam a busca de uma nova direção das políticas de alimentação e nutrição no final da década de 1990. O propósito da PNAN é "a garantia da qualidade dos alimentos colocados para consumo no País, a promoção das práticas alimentares saudáveis e a prevenção dos distúrbios nutricionais, bem como o estímulo às ações intersetoriais que propiciem o acesso universal aos alimentos". A perspectiva da promoção da saúde se apresenta e é apontada como uma das diretrizes da política: "promoção das práticas alimentares e estilos de vida saudáveis", cuja ênfase está na "socialização do conhecimento sobre alimentos e o processo de alimentação bem como acerca da prevenção dos problemas nutricionais, desde a desnutrição - incluindo as carências específicas - até a obesidade"

Fortemente comprometido com o combate à fome e com a garantia do direito à alimentação a todos os brasileiros, o Governo Federal instituiu em 2003 o Ministério Extraordinário da Segurança Alimentar e Combate à Fome - MESA, encarregado de coordenar 
uma política nacional de segurança alimentar e tendo como principal estratégia o Programa Fome Zero. Neste sentido, os diversos setores governamentais têm trabalhado de forma articulada, buscando integrar as suas ações, e, assim, concretizar a Segurança Alimentar e Nutricional no Brasil. O Ministério Extraordinário da Segurança Alimentar e combate á fome - MESA, tem como objetivo promover o direito humano à alimentação e à nutrição adequadas. As principais metas até 2007 consistem em: reduzir a taxa de desnutrição entre crianças menores de 5 anos de 5,7\% para 3,7\%; e reduzir a incidência de baixo peso ao nascer de 7,7\% para 5,7\%. Nesta área, as ações implementadas pelo Ministério da Saúde são embasadas nas diretrizes da Política Nacional de Alimentação e Nutrição - PNAN, publicada em 1999. Esta política, que integra a Política Nacional de Saúde e que tem como fundamento a segurança alimentar e nutricional e o direito humano à alimentação, propõe-se a garantir a qualidade dos alimentos colocados para consumo no país, promover práticas alimentares saudáveis e prevenir e controlar os distúrbios nutricionais, bem como estimular ações intersetoriais que propiciem o acesso universal aos alimentos (ABRINQ, 2004).

\subsection{ALIMENTAÇÃO ESCOLAR NO BRASIL: EVOLUÇÃO HISTÓRICA}

A distribuição de alimentos as crianças em idade escolar teve inicio na década de 30, através de medidas de fornecimento do desejum aos filhos de operários. As medidas foram implementadas pelo serviço de alimentação da Previdência Social - SAPS. Na época, foi elaboradas a legislação que visava instituir o “copo de leite escolar” e as "sopas escolares”. No entanto, tal iniciativa não foi estendida para o país como um todo, ficando restrita aos pólos industriais. A partir da segunda metade da década de 30 e durante a década de 40, liderado por Josué de Castro, o movimento da "nutrição social” contribuiu para que o governo do Estado Novo, de caráter populista, implementasse alguns programas na área de alimentação e nutrição dirigidos ás camadas populares (SILVA, 1996).

Segundo o mesmo autor, em 1945, foi instalada a Comissão Nacional de Alimentação (CNA), subordinada ao Conselho Federal de Comercio Exterior. Objetivava formular normas para a política nacional de alimentação e nutrição e estudar o estado nutricional e os hábitos 
alimentares da população (...) Em 1972, a Lei Federal de $n^{0}$ 5829/72, criou o Instituto Nacional de Alimentação e Nutrição, consolidadas no Programa Nacional de Alimentação - PRONAN (INAN). O INAN surgiu em um contexto sócio-político-institucional em que a política social passou a ser uma preocupação explícita do Estado, constituindo uma das metas do planejamento governamental. O PRONAN engloba, entre outros, o Programa Nacional de Alimentação Escolar - PNAE.

\section{Programa Nacional de Alimentação Escolar (PNAE)}

O PNAE é o programa que prevê a transferência de recursos federais para Estados, Municípios e o Distrito Federal, com o objetivo de comprar gêneros alimentícios para a Merenda Escolar, em caráter suplementar. O PNAE, também conhecido como "Merenda Escolar", é o mais antigo programa social do Governo Federal na área de Educação. Foi desenvolvido em 1954 e ganhou abrangência nacional em 1955, ou seja, dando a todos os alunos matriculados nos estabelecimentos públicos e nos mantidos por entidades filantrópicas, o direito a alimentação escolar, conforme prevê o Art. 208 da Constituição Federal (GDF, 1999).

O PNAE repassa recursos financeiros para garantir a oferta da alimentação escolar, de forma a suprir, no mínimo, 15\% das necessidades nutricionais dos alunos, durante o período de permanência na escola. Dessa forma, o Programa contribui para a melhoria da capacidade de aprendizagem, para a formação de bons hábitos alimentares, além de contribuir para a redução da evasão escolar. Com o PNAE, o Governo Federal vem cumprindo um importante papel social no País, uma vez que reconhece o direito à alimentação dos alunos da rede pública, conforme determina a Constituição Federal, garantindo o atendimento universal, sem qualquer discriminação (ME, 2005).

São atendidos pelo PNAE todos os alunos da Educação Infantil (creche e pré-escola) e do Ensino Fundamental matriculados em escolas públicas e filantrópicas cadastradas no censo escolar do Ministério da Educação, realizado pelo Instituto Nacional de Estudos e Pesquisas Educacionais (INEP). O repasse dos recursos é feito com base no censo escolar, realizado no ano anterior ao do atendimento. Logo no início de 2003, o PNAE igualou o valor per capita da pré- 
escola com o ensino fundamental - o valor passou de $\mathrm{R} \$ 0,06$ para $\mathrm{R} \$ 0,13$. As cidades que investiram na educação pré-escolar receberam aumentos significativos. Desde junho do ano passado, o Fundo Nacional de Desenvolvimento da Educação repassa a creches públicas e filantrópicas R\$ 0,18 por criança atendida. Quase 870 mil alunos de zero a três anos foram contemplados. A cobertura do PNAE-Creche é de 250 dias. Em outubro, o PNAE passou a atender todos os alunos das comunidades indígenas, graças a parceria firmada pelo MEC com o Ministério Extraordinário de Segurança Alimentar e Combate à Fome (ME, 2005).

O PNAE possibilita uma melhor qualidade de vida para 22\% da população brasileira ao desenvolver políticas de qualidade alimentar e nutricional. Além de contribuir para uma boa aprendizagem, o programa significa incentivo ao combate à fome e melhoria na alimentação dos alunos localizados nas regiões mais carentes. Outro ponto alto do Programa é a participação da sociedade civil como agente co-responsável no processo. Por meio dos Conselhos de Alimentação Escolar (CAE), o cidadão exerce sua responsabilidade social, fiscalizando e avaliando o desempenho do programa, fator indispensável para fazer da Alimentação Escolar uma referência brasileira na área da educação (ME, 2005).

O programa de alimentação escolar não deve se restringir apenas ao serviço de alimentação e de nutrição. Ao contrário, deve ampliar seu alcance, abrangendo todos os departamentos da escola, desde a diretoria até as áreas pedagógica, administrativa e operacional, não se esquecendo obviamente, dos familiares. Em resumo, o aluno bem alimentado apresenta melhor aproveitamento escolar, atinge o equilíbrio necessário para o seu crescimento e desenvolvimento, bem como mantém as defesas necessárias para uma boa saúde (AMODIO E FISBERG, 2005).

\subsection{PROGRAMA FOME ZERO E A EDUCAÇÃO ALIMENTAR}

O Programa Fome Zero é um conjunto de ações que estão sendo implementadas gradativamente pelo governo federal. O objetivo do Programa é promover a segurança alimentar a todos os brasileiros, atacando as causas estruturais da pobreza. As iniciativas envolvem vários 
ministérios, as três esferas de governo (federal, estadual e municipal) e a sociedade civil organizada. Para alcançar seus objetivos, o Fome Zero atua em três eixos: implantação de políticas públicas, construção participativa de uma política de segurança alimentar e nutricional e mutirão contra a fome. Entende-se por políticas públicas a implantação de ações estruturais, específicas e locais. A construção participativa da sociedade na formulação, execução e acompanhamento de uma Política Nacional de Segurança Alimentar e Nutricional está sendo desenvolvida em conferências municipais e estaduais que estão acontecendo por todo o Brasil. Já o mutirão contra a fome é um grande movimento nacional de solidariedade para atender emergencialmente aqueles que sofrem com a falta de alimentos e não podem esperar pelos resultados de mudanças profundas nas estruturas econômicas e sociais. As políticas estruturais são voltadas para combater as causas mais profundas da fome e da pobreza, buscando o desenvolvimento local e gerando renda e emprego e as específicas visam atender diretamente às famílias no acesso ao alimento. Já as políticas locais são implantadas pelos governos estaduais e pelas prefeituras (SESAN, 2004).

A proposta do Programa Fome Zero (PFZ), elaborado pelo Instituto da Cidadania, em 2001, corrobora as proposições da promoção de práticas alimentares saudáveis da PNAN. O documento contempla a importância da educação alimentar na prevenção tanto da desnutrição como da obesidade, ressaltando que a mesma "é, geralmente, negligenciada como política alimentar devido à priorização do ataque à causa principal da fome - a renda". No âmbito do “Fome Zero”, propõe-se "uma posição ativa do poder público no estabelecimento de campanhas publicitárias e palestras sobre educação alimentar e educação para o consumo, devendo esse aspecto da educação ser um dever do Estado, incluído como obrigatório no currículo escolar de primeiro grau". Também ao poder público cabe a responsabilidade pelo zelo das informações sobre alimentação saudável ao público, desde a própria produção da informação até sua distribuição e o controle, como também a formação e capacitação de recursos humanos. O PFZ reforça o papel do Estado na questão educacional e na estratégia das campanhas e do controle das informações, além da atuação na normatização da comercialização dos alimentos, explicitando a busca de um maior comprometimento ético da publicidade e da propaganda. Contudo, traz um conceito novo, além de utilizar o termo educação alimentar no lugar de educação alimentar e nutricional: a educação para o consumo, conceito que emerge das discussões sobre o direito do 
consumidor. Trata-se de uma das políticas específicas que prevê "uma série de ações que buscam informar e orientar a população em geral via os meios de comunicação, escolas, empresas e na família para que o brasileiro passe a ter mais consciência na hora de escolher o que levar à mesa" (SANTOS, 2005).

Segundo, o mesmo autor, até o presente momento, o PFZ em vigência está ainda mais voltado para os programas emergenciais, cujas atividades educativas estão também previstas como suporte das ações. Por exemplo, o Programa Bolsa Alimentação, cujos processos de gestão e execução foram unificados dentro do Programa Bolsa Família, objetivava aprimorar as ações de combate às carências nutricionais e contribuir para redução da alta prevalência de desnutrição e mortalidade infantil em todo o território nacional. O programa também concebia as atividades educativas em saúde e nutrição dentro da agenda de compromissos a serem estabelecidos com os beneficiários. No entanto, a concepção dessas ações educativas e a forma como elas se dão na prática cotidiana demandam estudos.

\subsection{LEI DAS CANTINAS ESCOLARES NO DISTRITO FEDERAL}

A Lei $n^{\circ} 3.695$ promulgada em 8 de novembro de 2005 de autoria dos Deputados Distritais Augusto Carvalho e Arlete Sampaio, dispõe sobre a promoção da alimentação saudável nas escolas da rede de ensino do Distrito Federal e determina que fica proibida a comercialização de balas, pirulitos, gomas de mascar, biscoitos recheados; refrigerantes e sucos artificiais; salgadinhos industrializados; frituras em geral; pipoca industrializada; bebidas alcoólicas; alimentos industrializados cujo percentual de calorias provenientes de gordura saturada ultrapasse $10 \%$ (dez por cento) das calorias totais; alimentos em cuja preparação seja utilizada gordura vegetal hidrogenada no ambiente das escolas de educação infantil, de ensino fundamental e médio das redes pública e privada de ensino. A lei também determina que a cantina escolar será administrada por pessoa devidamente capacitada em aspectos de alimentação e nutrição relevantes para o exercício do comércio de alimentos destinados à população infanto-juvenil (LEI $\left.\mathrm{N}^{0} 3.695,2005\right)$. 
A Lei determina também que a cantina escolar ofereça para consumo, diariamente, pelo menos uma variedade de fruta da estação in natura, inteira ou em pedaços, ou em forma de suco. Nenhuma escola poderá fazer publicidade de produtos cuja comercialização esteja proibida pela nova lei. A Secretaria de Saúde do DF ficará responsável pela fiscalização. A Gerência de Alimentação Escolar da Secretaria de Educação do DF já previa a resistência dos alunos. E dos donos de cantina também. As escolas da rede pública com cantinas terceirizam os espaços e também terão de dar o exemplo (SESDF, 2005).

É preciso insistir que, não basta proibir a venda desses alimentos, devem-se adotar formas atrativas de trabalhar a reeducação e educação nutricional das crianças e adolescentes, abordando temas como: alimentação e cultura, refeição balanceada, grupos de alimentos e suas funções, alimentação e mídia, hábitos e estilos de vida saudáveis, frutas e hortaliças: preparo, consumo e sua importância para a saúde, fome e segurança alimentar, dados científicos sobre malefícios do consumo dos alimentos cuja comercialização é vedada por esta lei (DF, 2005).

Segue em anexo a lei 3.695 na íntegra. 


\section{PROJETO: CULTURA ALIMENTAR E QUALIDADE DE VIDA}

A prevenção a obesidade infantil e também o baixo peso, quando ele existir, é fundamental na fase escolar, já que na escola, a criança faz pelo menos uma refeição e neste ambiente é possível trabalhar de forma transversal noções de alimentação, tornando a criança um agente modificador na família

O comportamento alimentar das crianças assim como as suas preferências alimentares são influenciadas por fatores genéticos ou hereditários e também por fatores ambientais. As influências a que são submetidas poderão levar a um quadro de baixo peso ou de sobrepeso e ambos causarão problemas no desenvolvimento e crescimento da criança.

O Projeto Cultura Alimentar e Qualidade de Vida se propõem a atuar modificando comportamentos alimentares quando inadequados á saúde, e promover a saúde pela introdução de práticas alimentares mais adequadas.

O projeto atuou no processo de educação alimentar com ações específicas, pontuadas a seguir:

\section{AVALIAÇÃO ANTROPOMÉTRICA DOS ALUNOS DA EDUCAÇÃO INFANTIL}

A leitura do estado nutricional é feita através de percentis, que são a medida estatística proveniente da divisão de uma série de observações em cem partes iguais, estando os dados ordenados do menor para o maior, em que cada ponto da divisão corresponde a um percentil. Percentil é a forma de classificação adotada pelo Ministério da Saúde para uso em serviços de saúde, por meio do Cartão da Criança.

Os resultados não devem traçar um diagnóstico de forma isolada, pois como já foi explanado, a relação peso / idade não considera em que momento a criança apresentou um déficit de peso, ou seja, pode ter havido uma perda de peso em um momento específico e que inclusive já 
foi recuperada, mas continua sendo apontada. Ou um peso superior ao esperado para idade pode se apresentar como diagnóstico em um momento que a criança já tenha alcançado o seu peso normal para a idade cronológica. O diagnóstico será confirmado quando a relação altura / idade for determinada, pois este índice considera o crescimento linear da criança, ou seja, se houve alguma intercorrência em alguma fase da vida que já foi corrigida, não haverá reflexos futuros no crescimento e desenvolvimento desta criança . Quando o índice de altura / idade se apresenta alterado, também devem ser investigadas as heranças genéticas.

\section{INQUÉRITO DIETÉTICO}

A freqüência alimentar é um retrospecto da ingestão de alimentos, isto é, alimento por dia, por semana ou por mês, fornece informações qualitativas sobre o consumo alimentar, não fornecendo dados quantitativos. Para facilidade da avaliação, a freqüência alimentar organiza os alimentos em grupos que têm nutrientes em comum. Desta forma é possível observar se o consumo alimentar está de acordo com as necessidades de nutrientes (carboidratos, lipídios, proteínas, vitaminas, cálcio, ferro, etc). Com esta informação, se o consumo estiver inadequado serão apontados os nutrientes em déficit sendo traçadas estratégias a favor da ingestão dos alimentos que no passado foram recusados.

Em geral as crianças tendem a rejeitar alimentos que não lhe são familiares. Esse tipo de comportamento já se manifesta em crianças de apenas seis meses de idade. Porém, com exposições freqüentes, os alimentos novos passam a ser aceitos, podendo ser incorporados à dieta da criança. Em média são necessárias de oito a dez exposições a um novo alimento para que ele seja aceito pela criança. Muitos pais, talvez por falta de informação, não entendem esse comportamento como sendo normal de uma criança e interpretam a rejeição inicial pelo alimento como uma aversão permanente ao alimento, desistindo de oferecê-lo á criança. Outra forma de introduzir novos alimentos ou alimentos inicialmente rejeitados é através da mudança das preparações e apresentação

É desejável que a criança ingira alimentos com baixos teores de açúcar e sal, de modo a que esse hábito mantenha-se na sua fase adulta.Uma vez acostumados com um certo nível de açúcar 
ou sal, a tendência da criança é de rejeitar outras formas de preparação do alimento (Sullivan e Birch, 1990).

Um fator que pode limitar a ingestão de uma dieta variada é o consumo de dietas altamente calóricas, saciando rapidamente a criança, o que impede a ingestão de outros alimentos. Estudos demonstraram que crianças aprendem a preferir o sabor de alimentos com alta densidade energética, principalmente alimentos doces e gordurosos como refrigerantes, balas, chocolates, frituras, etc (Birch et al. 1990).

\section{KIT SABOROSO}

O Kit saboroso é uma idéia que acompanha o Projeto Cultura Alimentar e Qualidade de Vida, direcionado às crianças da educação infantil. O Kit pode ser preparado na própria lanchonete da escola ou produzido em casa, já que o cardápio é enviado semanalmente via agenda para as famílias com três opções de lanche (opção 1, opção 2 e opção light).

A principal justificativa do kit saboroso é: As crianças em idade de 3 a 6 anos encontramse em uma fase de socialização intensa e com o apetite reduzido e seletivo, com isso resolvemos enfocar a alimentação saudável com o "Projeto Cultura Alimentar e Qualidade de vida”. As crianças quando se alimentam juntamente com outras em um ambiente adequado freqüentemente alimentam-se melhor do que quando estão sozinhas. O cardápio do lanche deve conter alimentos de todos os grupos (construtores, energéticos e reguladores); em proporção adequada e com variação ao máximo dos alimentos.

O Kit Saboroso está de acordo com a RDA, quota diária recomendada de nutrientes, usada como um guia na determinação de energia. Recomenda-se para crianças de 3 a 6 anos uma dieta de 1300 a 1800 kcal que é o suficiente para suprir suas necessidades diárias considerando uma criança saudável, que se fracionarmos em 6 refeições diárias, o lanche escolar estaria equivalendo à aproximadamente $270 \mathrm{kcal}$. 


\section{ATIVADES PRÁTICAS E LÚDICAS EM EDUCAÇÃO NUTRICIONAL}

Durante o ano de 2005 além das atividades descritas acima foram desenvolvidas diversas atividades de impacto no processo de educação nutricional.

SABADÃO CULTURAL: Encontro de profissionais de saúde e educação para educação infantil e ensino fundamental. Neste evento vários profissionais expõem em estandes as suas atividades, dessa forma as crianças têm o primeiro contato com as diversas profissões. Esta atividade é uma iniciativa da escola.

JORNAL INFORMATIVO: “Jornalzinho”: Projeto Cultura Alimentar e Qualidade de Vida, que informa aos pais e colaboradores sobre as ações do projeto, para que a família participe e reforce o processo de aprendizagem em educação nutricional. O "Jornalzinho" foi enviado as famílias via agenda.

PALESTRA: Ministrada aos pais e responsáveis dos alunos da educação infantil - Tema: Alimentação infantil na fase pré-escolar e a importância do lanche na escola.

DIA DA AMIZADE EM COMEMORAÇÃO AO DIA DAS MÃES: Neste evento foram desenvolvidas duas atividades: A salada de frutas comunitária e a avaliação antropométrica das mães dos alunos da educação infantil e ensino fundamental.

FESTA JUNINA: As festas juninas realizadas nos meses de junho e julho, normalmente envolvem em suas comemorações comidas típicas de alto calor valor calórico. Considerando que estas festas ocorrem de forma esporádica não foram determinadas ações específicas de intervenção nutricional para o evento. Como material educativo foram desenvolvidos cartazes com as informações nutricionais de todos alimentos comercializados na festa, com o cálculo de calorias para porções de $100 \mathrm{~g}$ de alimento. 
AULA TEÓRICA: PIRÂMIDE DOS ALIMENTOS: Nesta atividade, foi trabalhado com as crianças noções de quantidade e qualidade na escolha dos alimentos através do recorte e pintura da pirâmide alimentar.

CONTO DIDÁTICO: SE EU FOSSE UM TOMATE: Trata-se de uma estória em que uma criança se transforma em um tomate e leva as crianças a discutirem os benefícios de consumir frutas e hortaliças.

DIA DA AMIZADE EM COMEMORAÇÃO AO DIA DOS PAIS: Neste evento foi desenvolvida uma atividade prática em que as crianças preparavam um sanduíche saudável para os pais presentes no momento das oficinas.

PEÇA TEATRAL: O BRANCO DE FOME E OS TRÊS GIGANTES: Uma adaptação da estória a "Branca de neve e os sete anões”. A peça trata o tema - educação nutricional e formação de padrões alimentares na fase pré-escolar.

PROGRAMA: CONHECENDO AS HORTALIÇAS NA ESCOLA: Esta atividade encerrou uma aula prática em que as crianças participaram de todo processo da produção de uma salada. Desde da compra das hortaliças, higienização, preparo e degustação.

LANCHE COMUNITÁRIO: Este evento encerrou as atividades do projeto Cultura Alimentar e Qualidade de Vida no ano de 2005. A equipe de nutrição preparou para as crianças um lanche saudável, de forma a proporcionar alimentos que satisfizessem os anseios infantis, mas também inserindo novos alimentos, considerados mais benéficos a saúde tais como a ricota, blanquet de peru, etc. 


\section{CONCLUSÃO}

A escola é a melhor janela de oportunidade para prevenir a obesidade infantil e também o baixo peso quando ele existir. Hoje, a alimentação escolar é um assunto de tamanha relevância, que Estado e sociedade se unem e através de políticas publicas e outras ações tratando o tema com valoroso empenho, a exemplo disso, temos no Distrito Federal, a Lei n. 3.695 de 8 de novembro de 2005, relativa à promoção de uma alimentação mais saudável nas escolas, proibindo a comercialização de inúmeros produtos no ambiente das escolas, bem como: balas, pirulitos, gomas de mascar e biscoitos recheados; refrigerantes e sucos artificiais; salgadinhos industrializados; frituras em geral; pipoca industrializada; bebidas alcoólicas; alimentos industrializados cujo percentual de calorias proveniente de gordura saturada ultrapasse $10 \%$ das calorias totais; alimentos em cuja preparação seja utilizada gordura vegetal hidrogenada, etc.

A criança quando está mal nutrida pode ter retardo na eficiência física e pode sentir fraqueza muscular, fora isso, pode tornar-se morosa, irritada e sem iniciativa. Portanto, a nutrição adequada é essencial para o desenvolvimento das funções normais do organismo.

A formação dos padrões alimentares da criança depende principalmente da orientação dos pais e responsáveis, que devem atentar para a importância de consumir alimentos saudáveis e também oferecer estes alimentos às crianças. A imposição de regras alimentares às crianças não adianta se a família não der um bom exemplo. Uma criança que é habituada a sentar-se a mesa com a família e pode observar que todos consomem hortaliças e frutas, provavelmente irá adquirir bons hábitos alimentares. Por outro lado, é importante lembrar que, assim como os adultos as crianças também tem preferências alimentares e eventualmente podem não gostar de um alimento ou outro. O ideal é não forçar a criança a ingerir os alimentos que rejeita, pois isso transformará o horário das refeições em um momento desagradável, prejudicando a ingestão alimentar, os pais, responsáveis e educadores devem incentivar as crianças, mesmo que através de subterfúgios. Quando a criança não aceita um alimento específico deve-se tentar substituí-lo por outro alimento que tenha o mesmo valor nutricional e que forneça as mesmas vitaminas. 
É importante que a família compreenda o significado do alimento, do ato de comer e a importância de como oferecê-lo à criança, pois muitas vezes elas só aceitam determinados alimentos por ter observado os pais ingerirem também. Por outro lado, criança se habitua a comer só o que gosta, quando outro alimento for oferecido, a criança recusa, pois não quer comer alimentos diferentes e se os pais permitem, a criança se afastará cada vez mais de adquirir bons hábitos alimentares. A formação dos padrões alimentares envolve outras questões além das nutricionais, a relação emocional entre a criança e a família é fundamental para a aceitação dos alimentos. A valorização dos momentos de alimentação em família também é determinante. Alguns fatores podem desencadear a negação parcial dos alimentos, são eles: um ambiente familiar conturbado, socialização intensa, ausência da família, nascimento de um irmão, separação dos pais, quando os pais aceitam manipulação por parte da criança, neofobia, etc.

Durante o período pré-escolar, as crianças passam por uma mudança importante de padrão alimentar. Nesta fase, já participam das atividades familiares como também das refeições dos adultos, recebendo o mesmo alimento que a família come. À medida que crescem, diminuem o número de refeições e o interesse pela alimentação. Com o ingresso à escola passam a conviver com horários, o conhecimento de alimentos diferentes daqueles já habitualmente conhecidos no meio familiar e aumenta as preferências por doces, guloseimas, bebidas de alto valor calórico e baixo valor nutritivo.

Todo um estilo de vida inadequado representado por sedentarismo, hábitos familiares incorretos, alimentação insatisfatória, refeições desequilibradas, consumo de doces, guloseimas, dentre outros favorece o aparecimento da obesidade. Devido a dificuldade em obter-se sucesso no tratamento da obesidade na vida adulta, é necessário desenvolver programas de intervenção ainda na infância.

Uma boa nutrição é a condição fundamental para a saúde e essencial para manutenção do crescimento de crianças. Para que a nutrição adequada funcione, precisamos aprender combinar os alimentos de forma que eles nos forneçam todos os nutrientes necessários. 


\section{REVISÃO BIBLIOGRÁFICA}

1. ALMEIDA, Sebastião. Propaganda de alimentos, hábitos alimentares na infância e risco de obesidade. Laboratório de nutrição e comportamento. Setor: Psicologia FFCLRP, USP, 2003.

2. ALMEIDA, Sebastião de Sousa, NASCIMENTO, Paula Carolina BD e QUAIOTI, Teresa Cristina Bolzan. Quantidade e qualidade de produtos alimentícios anunciados na televisão brasileira. Rev. Saúde Pública, jun. 2002, vol.36, no.3, p.353-355. ISSN 00348910.

3. AMODIO, Martha F. Paschoa e FISBERG, Mauro. Alimentação Escolar, 2005. http://www.pontocritico.com.br/nutricao/genaf.htm

4. ANDRADE, Maria G. O desenvolvimento das escolhas alimentares em crianças e adolescentes. IBER PSICOLOGIA.Escola Superior de Tecnologia da Saúde de Lisboa. $2^{\circ}$ congresso Hispano-português de psicologia, 10.2.11, 2005.

5. BARROS, Denise C. SILVA, Denise O., SILVA, Érica R. Concepções e percepções de professores, crianças e adolescentes do ensino fundamental sobre alimentação e nutrição para identificação e definição de um circuito básico de informação ecomunicação para a promoção da alimentação saudável no museu da vida da fundação oswaldo cruz, 2005.

6. BLEIL, S.L.. O padrão alimentar ocidental: considerações sobre as mudanças de hábitos no Brasil. Cadernos de debates, v. VI, p 1-25. 1998.

7. BORSARI, ANDRÉIA P., CRUZ, Gabriela, LOLLI, Juliano, OLIVEIRA, Rosimeire R. e SANTOS, Silvone H. Santos. Educação nutricional para crianças de 7 a 11 anos de uma comunidade do município de Araraquara. UNIARA - Centro Universitário de Araraquara, 2005. 
8. CAVAlCANTE, A. Augusta M., PRIORE, Silvia Eloiza and FRANCESCHINI, Sylvia do Carmo Castro. Food consumption studies: general methodological aspects and its use in the evaluation of children and adolescents aged. Rev. Bras. Saude Mater. Infant., July/Sept. 2004, vol.4, no.3, p.229-240. ISSN 1519-3829.

9. COLUCCI, Ana Carolina A., PHILIPPI, Sonia Tucunduva e SLATER, Betzabeth. Desenvolvimento de um questionário de freqüência alimentar para avaliação do consumo alimentar de crianças de 2 a 5 anos de idade. Ver. Bras. Epidemiol., 2004; 7(4): 393-401.

10. COSTA, Ester de Queirós, RIBEIRO, Victoria Maria Brant e RIBEIRO, Eliana Claudia de Otero. Programa de alimentação escolar: espaço de aprendizagem e produção de conhecimento. Rev. Nutr., set./dez. 2001, vol.14, no.3, p.225-229. ISSN 1415-5273

11. DAVANCO, Giovana Mochi, TADDEI, José Augusto de Aguiar Carrazedo and GAGLIANONE, Cristina Pereira. Knowledge, attitudes and practices of teachers of basic cycle, exposed and non exposed to a Nutrition Education Course. Rev. Nutr., Apr./June 2004, vol.17, no.2, p.177-184. ISSN 1415-5273.

12. FILHO, Malaquias B., RISSIN, Anete. A transição nutricional no Brasil:tendências regionais e temporais. Cad. Saúde Pública, Rio de Janeiro, 19(Sup. 1):S181-S191, 2003.

13. FORATO, Ana. Lúcia, S. C., ARAUJO, Raquel M. A., QUEIROZ, Valéria M. V., COELHO, Maria S. L., BITENCOURT, Maria Cristina B. PRONAC - Programa de treinamento de professores na transmissão de informações sobre nutrição e alimentação da criança. Universidade Federal de Viçosa - Pró Reitoria de Extensão e Cultura, 2003. 
14. FUNDAÇÃO ABRINQ. Plano presidente amigo da criança e do adolescente. República Federativa do Brasil, I relatório semestral de acompanhamento. Novembro, 2004 / 2007.

15. GIUGlianO, R., MELO, Ana L. P. Diagnóstico de sobrepeso e obesidade em escolares:utilização do índice de massa corporal segundo padrão internacional. Jornal de Pediatria - Vol. 80, N², 2004.

16. GOUVEIA, E. L. C.. Nutrição saúde e comunidade. $2^{\mathrm{a}}$ edição. Rio de Janeiro. Editora Revinter, 1999.

17. GOVERNO DO DISTRITO FEDERAL, SECRETARIA DO ESTADO DE EDUCAÇÃO. Alimentação escolar do distrito federal - PNAE/DF, 1999. www.se.df.gov.br/gcs/file.asp?id=2688

18. GOVERNO DO DISTRITO FEDERAL， SECRETARIA DO ESTADO DE EDUCAÇÃO. Uma proibição difícil de engolir, 2005. http://www.fhdf.gov.br/mostraPagina.asp?codServico=782\&codPagina=9195.

19. IMETRO, IDEC. Publicidade e consumo. República Federativa do Brasil, 2002.

20. LOPEZ, Fábio Ancona, TADDEI, José Augusto. Educar em vez de limitar merenda escolar. Revista Isto é - Gente/Coluna: Saúde, fevereiro, 2005.

21. MAZZILLI, Rosa Nilda. Valor nutricional da merenda e sua contribuição para as recomendações nutricionais do pré-escolar, matriculado em CEAPE. Rev. Saúde Pública, June 1987, vol.21, no.3, p.246-254. ISSN 0034-8910. 
22. MINISTÉRIO DA EDUCAÇÃO (BRASIL) FNDE / Programas / Merenda Escolar., alimentação escolar, 2005-10-10 FNDE - Fundo Nacional de Desenvolvimento da Educação. www.fnde.gov.br/programas/pnae/

23. MINISTÉRIO DA SAUDE (BRASIL). Fundamentos técnico-científicos e orientações práticas para o acompanhamento do crescimento e desenvolvimento. Vol.1. Brasília: Ministério da Saúde, 2001.

24. NEVES, Márcia B. P.. O papel da educação nutricional, a respeito da alimentação saudável para 0 pré-escolar escolar. http://www.sopape.com.br/SPP\%20SociedadeParaense\%20de\%20Pediatria_arquivos/ali mentacao_escolar.htm

25. NOVAES, J. P., BORGES, A E. B., PRIORE, S.E., FRANCESCHINI S.C.C. Fatores associados a obesidade na infância e na adolescência. Ver. Nutrição Brasil, ed. jan/fev. 2003.

26. OLIVEIRA, C.L. FISBERG, M. Obesidade na infância e adolescência - uma verdadeira epidemia. Arquivos brasileiros de endocrinologia e metabologia.Vol 47, $\mathrm{n}^{\circ} 2$, abril de 2003.

27. PASQUA, Daiane Ap., JATOBÁ, Letícia, CARDOSO, Maria Fernanda C., LIMONI, Taís Fernanda. Educação alimentar para crianças de $1^{\mathrm{a}}$ e $\mathbf{2}^{\mathrm{a}}$ séries. UNIARA - Centro Universitário de Araraquara, 2005.

28. POULAIN, Jean-Pierre e PROENCA, Rossana Pacheco da Costa. O espaço social alimentar: um instrumento para o estudo dos modelos alimentares. Rev. Nutr., jul./set. 2003, vol.16, no.3, p.245-256. ISSN 1415-5273. 
29. SAMPAIO, Arlete, CARVALHO, Augusto, BARCELLO, Fabio. LEI No 3.695, 8 de novembro de 2005, dispõe sobre a promoção da alimentação saudável nas escolas da $\begin{array}{lllll}\text { rede de } & \text { ensino }\end{array}$ http://www.arletesampaio.net/doc/leis/lei_3695_05.htm

30. SANTOS Elisabete B., OLIVA Carlos A. G., AMÂNCIO O. M. Antropometria, composição corporal e estado nutricional em ferro, cobre e zinco em crianças e adolescentes de duas favelas de são paulo. The Electronic Journal of Pediatric Gastroenterology, Nutrition and Liver Diseases, 2006.

31. SANTOS, Ligia Amparo da Silva. Food and nutrition education in the context of promoting healthy food practices. Rev. Nutr., Sept./Oct. 2005, vol.18, no.5, p.681-692. ISSN 1415-5273.

32. SESAN. Principais ações implementadas pelo programa fome zero. São Paulo, Expo Fome Zero, 2004. http://www.fomezero.gov.br/download/balanco.pdf.

33. SILVA, Marina V.. A trajetória do programa de merenda escolar (1954 - 1994) e o estado nutricional de crianças brasileiras. Cadernos de nutrição 11:31-49,1996.

34. SZARFARC.S.C., GAMBARDELLA, A. M.D., TUDISCO, E.S.VANNUCCHI E. A avaliação do consumo energético: o uso de curvas padronizadas. Cad Nut 1994;7:4764

35. TAGLIARI, Paulo Sérgio. Merenda orgância chega nas escolas catarinenses. Revista agropecuária catarinense, v.15, n. 2, p. 30-36, jul, 2002.

36. TONIAL, Sueli Rosina. The challenges of nutritional care in the face its complexity in Brazil. Ciênc. saúde coletiva, 2002, vol.7, no.2, p.227-234. ISSN 1413-8123. 
37. TRICHES, Rozane Márcia e GIUGLIANI, Elsa Regina J. Obesidade, práticas alimentares e conhecimentos de nutrição em escolares.Secretaria de Educação da Prefeitura Municipal. Dois Irmãos, RS, Brasil. Departamento de Pediatria da Universidade Federal do Rio Grande do Sul. Porto Alegre, RS, Brasil.

38. UNB. Projeto de Atenção Nutricional as Creches do Distrito Federal. Universidade de Brasília, Faculdade de ciências da Saúde Departamento de Nutrição, 2005 www.unb.br/fs/creche/introducao2.htm

39. UNIFESP, COMUNICAÇÃO - Assessoria de Imprensa. Sugestões de Pauta. Evento inédito discute papel da propaganda na obesidade infantil, 2005. www.hsp.epm.br/comunicacao/index.htm

40. VIEIRA, Valéria C. R. PRIORE, Silvia E. RIBEIRO, Sônia M. R. FRANCESCHINI, Sylvia C.C. Alterações no padrão alimentar de adolescentes com adequação pônderoestatural e elevado percentual de gordura corporal. Rev. Bras. Saúde Matern. Infant., Recife, 5 (1): 93-102, jan. / mar., 2005 


\section{ANEXO I}

LEI No 3.695, 8 de novembro de 2005

\section{(Autoria do Projeto: Deputados Distritais Augusto Carvalho e Arlete Sampaio)}

Dispõe sobre a promoção da alimentação saudável nas escolas da rede de ensino do Distrito Federal

O Presidente da Câmara Legislativa do Distrito Federal promulga, nos termos do $\S 6^{\circ}$ do art. 74 da Lei Orgânica do Distrito Federal, a seguinte Lei, oriunda de Projeto vetado pelo Governador do Distrito Federal e mantido pela Câmara Legislativa do Distrito Federal:

Art. $1^{\circ}$ A promoção da alimentação saudável no âmbito das escolas de educação infantil e de ensino fundamental e médio das redes pública e privada do Distrito Federal é regulada por esta Lei.

Parágrafo único. As ações relativas à promoção da alimentação saudável envolverão toda a comunidade escolar, compreendidos alunos e suas famílias, professores, funcionários da escola, proprietários e funcionários de cantinas escolares.

Art. $2^{\circ}$ As cantinas escolares e qualquer outro comércio de alimentos que se realize no ambiente escolar obedecerão aos princípios desta Lei. 
Art. $3^{\circ}$ A cantina escolar será administrada por pessoa devidamente capacitada em aspectos de alimentação e nutrição relevantes para o exercício do comércio de alimentos destinados à população infanto-juvenil.

$\S 1^{\circ}$ A capacitação referida no caput será de, pelo menos, 15 (quinze) horas-aula e constará, no mínimo, de aspectos de higiene dos alimentos, valor nutricional dos alimentos, importância dos nutrientes para a promoção da saúde, métodos adequados de preparo de alimentos para promoção da saúde, as boas práticas de serviços de alimentação, aprovadas pela RDC nº 216, de 2004, da Agência Nacional de Vigilância Sanitária.

$\S 2^{\circ}$ A capacitação do responsável pela cantina, reconhecida pelo Poder Público e feita por profissional nutricionista, é condição necessária para concessão de alvará de funcionamento do estabelecimento.

$\S 3^{\circ}$ Os responsáveis por cantinas escolares já instaladas terão o prazo de cento e oitenta dias, a contar da publicação desta lei, para passarem por curso de capacitação referido no caput.

$\S 4^{\circ}$ O Poder Público realizará, diretamente ou por meio de cursos de Nutrição de instituições de ensino superior credenciadas ou Entes de Cooperação da Administração Pública, a capacitação dos responsáveis pelas cantinas escolares.

Art. $4^{\circ}$ Fica proibida a comercialização dos produtos a seguir relacionados no ambiente das escolas de educação infantil, de ensino fundamental e médio das redes pública e privada de ensino:

I - balas, pirulitos, gomas de mascar, biscoitos recheados;

II - refrigerantes e sucos artificiais;

III - salgadinhos industrializados;

IV - frituras em geral; 
V - Pipoca industrializada;

VI - Bebidas alcoólicas;

VII - Alimentos industrializados cujo percentual de calorias provenientes de gordura saturada ultrapasse $10 \%$ (dez por cento) das calorias totais;

VIII - Alimentos em cuja preparação seja utilizada gordura vegetal hidrogenada.

$\S 1^{\circ}$. A proibição de que trata este artigo estende-se aos ambulantes localizados nas cercanias das escolas.

$\S 2^{\circ}$ As cantinas instaladas em escolas de ensino médio, que não atendam a crianças dos demais níveis de ensino, deverão adequar-se ao disposto no caput, progressivamente, no prazo de três anos.

Art. $5^{\circ}$ A cantina escolar oferecerá para consumo, diariamente, pelo menos uma variedade de fruta da estação in natura, inteira ou em pedaços, ou na forma de suco.

Art. $6^{\circ}$ Os sucos de frutas, as bebidas lácteas e demais preparações cuja adição de açúcar é opcional serão oferecidas ao consumo conforme a preferência do consumidor pela adição ou não do ingrediente.

Parágrafo único. A adição de açúcar, quando solicitada pelo consumidor, não poderá exceder a dois saches de 5 (cinco) gramas por porção de 200(duzentos) mililitros.

Art. $7^{\circ} \mathrm{O}$ contrato entre a escola e a cantina escolar, quando for o caso, conterá cláusulas observantes desta Lei.

Parágrafo único. Nas concorrências públicas, a minuta de contrato que integra o respectivo edital para exploração dos serviços de cantina escolar conterá cláusulas especificando itens comercializáveis, com observância do disposto nesta Lei. 
Art. $8^{\circ}$ É proibida no ambiente escolar a publicidade de produtos cuja comercialização seja proibida por esta lei.

Parágrafo único. A proibição constante deste artigo estende-se a modalidades de publicidade por meio de patrocínio de atividades escolares, inclusive extracurriculares.

Art. 9. As escolas adotarão conteúdo pedagógico e manterão em exposição material de comunicação visual sobre os seguintes temas:

I - Alimentação e Cultura;

II - refeição balanceada, grupos de alimentos e suas funções;

III - alimentação e mídia;

IV - hábitos e estilos de vida saudáveis;

V - frutas, hortaliças: preparo, consumo e sua importância para a saúde;

VI - fome e segurança alimentar;

VII - dados científicos sobre malefícios do consumo dos alimentos cuja comercialização é vedada por esta Lei.

Parágrafo único. As escolas promoverão a capacitação de seu corpo docente para a abordagem multidisciplinar e transversal desses conteúdos.

Art. 10. As escolas e respectivas cantinas terão prazo de 180 (cento e oitenta) dias para se adequarem ao disposto nesta Lei.

Art. 11. As infrações aos dispositivos desta lei e de seu regulamento sujeitarão o infrator às penalidades previstas na Lei ${ }^{\circ}$ 6.437, de 20 de agosto de 1977. 
Art. 12. O Poder Executivo regulamentará esta Lei no prazo de sessenta dias.

Art. 13. Cabe aos órgãos de vigilância sanitária e de educação, com a colaboração das Associações de Pais e Mestres, a fiscalização do disposto nesta Lei, respeitadas as respectivas competências.

Art. 14. As despesas decorrentes da aplicação desta Lei correrão à conta de dotações próprias consignadas em orçamento.

Art. 15 Esta Lei entra em vigor na data de sua publicação.

Art. 16. Revogam-se as disposições em contrário.

Brasília, 10 de novembro de 2005

Deputado FÁBIO BARCELLOS

Presidente 
